\title{
Left Ventricular Thrombus and Subsequent Thromboembolism, Comparison of Anticoagulation, Surgical Removal, and Antiplatelet Agents
}

\author{
Joo Myung Lee ${ }^{1}$, Jin Joo Park ${ }^{1}$, Hee Won Jung ${ }^{1}$, Young-Seok Cho², Il-Young Oh², Chang-Hwan Yoon², \\ Jung-Won Suh², Eun Ju Chun², Sang II Choi², Tae-Jin Youn², Cheong Lim², Goo-Yeong Cho², \\ In-Ho Chae ${ }^{2}$, Kay-Hyun Park² and Dong-Ju Choi ${ }^{2}$
}

${ }^{1}$ Seoul National University Hospital, Seoul, South Korea

${ }^{2}$ Seoul National University Bundang Hospital, Seongnam, South Korea

\begin{abstract}
Aim: Left ventricular (LV) thrombus is one of the risk factors for systemic thromboembolism. The aims of this study were to compare the long-term clinical outcomes of LV thrombus using current therapeutics, anticoagulation, operative treatment, and antiplatelet agents and to identify independent predictors of systemic thromboembolism.

Methods: We screened 86,374 patients for intracardiac thrombus in the electronic medical records and imaging databases. Records of 62 patients with LV thrombus, diagnosed between May 2003 to November 2011, were comprehensively reviewed regarding baseline characteristics, imaging data and thrombus outcomes, thromboembolic events and treatment complications by treatment group.

Results: The majority $(80.6 \%)$ had ischemic etiology. Systemic thromboembolism developed in 18 patients; 8 (45\%) were post-treatment thromboembolisms while 10 events occurred before treatment began. No post-treatment thromboembolism occurred in the operative treatment group; in contrast, 7 post-treatment thromboembolisms occurred in anticoagulation group $(17 \%)(\log \operatorname{rank} p=0.175)$. Independent predictors of post-treatment thromboembolism were dilated cardiomyopathy (HR 61.30, $p=0.001$ ), previous cerebrovascular events (HR 7.06, $p=0.042$ ), female gender (HR 7.11, $p=0.031$ ), and echocardiographic left ventricular end-diastolic diameter (HR 1.15, $p=0.047)$.

Conclusions: In this study, the rate of post-treatment thromboembolism was not significantly different among the treatment groups; however, operative treatment tended towards less post-treatment thromboembolism than other treatment groups.
\end{abstract}

J Atheroscler Thromb, 2013; 20:73-93.

Key words, Acute myocardial infarction, Dilated cardiomyopathy, Ischemic cardiomyopathy, Intracardiac thrombus, Left ventricular thrombus

\section{Introduction}

Left ventricular (LV) thrombus formation is a frequent complication of ischemic heart disease, particularly in acute myocardial infarction (MI), even

Address for correspondence: Young-Seok Cho, Seoul National University and Seoul National University Bundang Hospital, 166 Gumi-ro, Bundang, Seongnam, Gyeonggi, 463-707, South

Korea

E-mail: flammeus@snubh.org

Received: June 22, 2012

Accepted for publication: July 16, 2012 after successful revascularization ${ }^{1)}$. At least $5 \%$ of patients develop LV thrombus after acute $\mathrm{MI}^{2)}$. Various other conditions, including idiopathic dilated cardiomyopathy (DCMP), stress-induced cardiomyopathy and valvular heart disease-induced severe LV dysfunction, are known risk factors for LV thrombus formation $^{3,4)}$.

The clinical relevance of LV thrombus is the association with increased risk of systemic arterial thromboembolism ${ }^{5-7)}$. It is known that anticoagulation therapy with warfarin reduces both the risk of LV thrombus formation and subsequent thromboembo- 


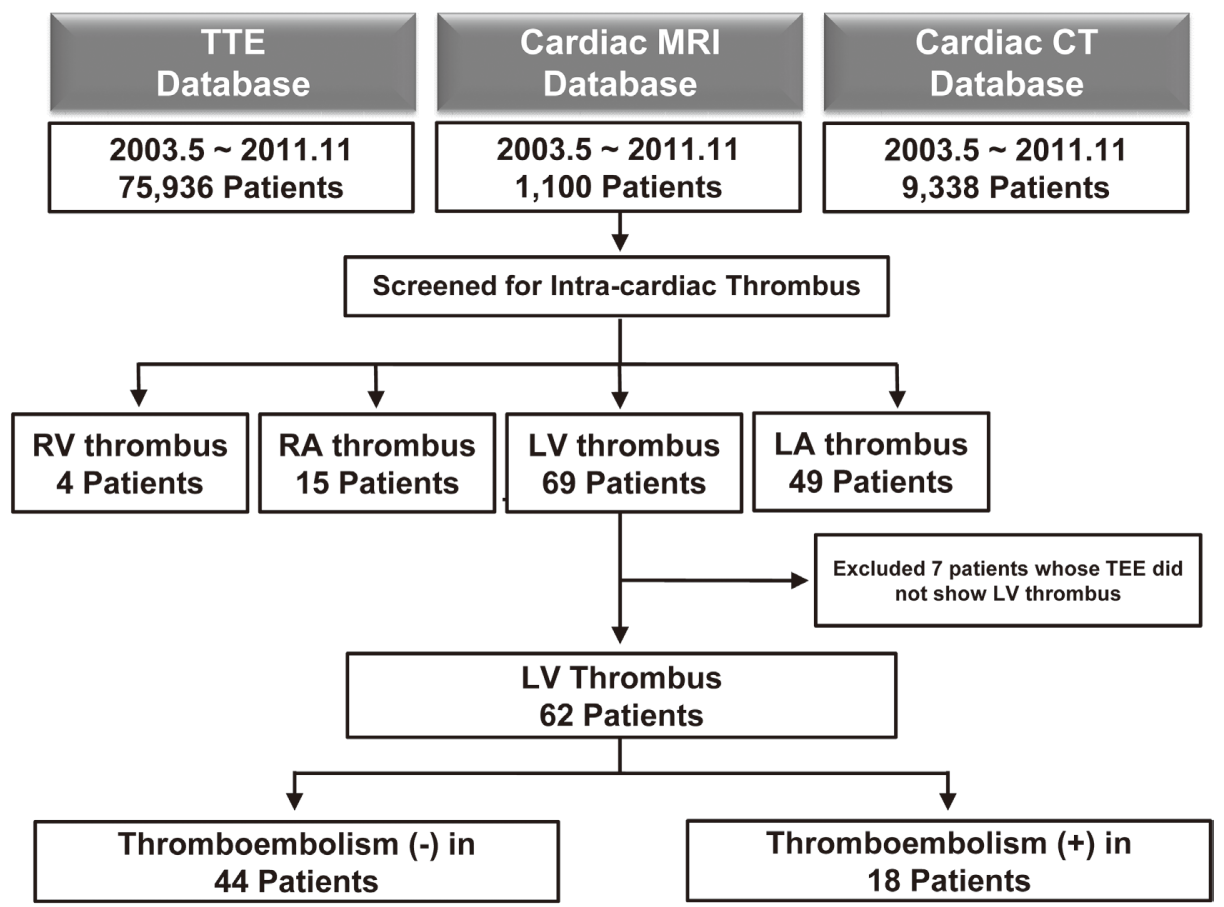

Fig. 1. Flow of Participants Diagram.

TTE denotes trans-thoracic echocardiography, TEE trans-esophageal echocardiography, MRI magnetic resonance imaging, CT computed tomography.

Abbreviations: LA, left atrium; LV, left ventricle; RA right atrium; RV right ventricle.

lism, but increases the risk of bleeding ${ }^{7-9)}$. Current ACC/AHA guidelines recommend anticoagulation with warfarin for patients with LV thrombus or cardioembolic stroke (class I, level of evidence: $b)^{10)}$; however, chronic anticoagulation has inevitable bleeding complications.

Moreover, the long-term consequences and frequency of systemic thromboembolism after conventional anticoagulation for LV thrombus have not been sufficiently investigated. Evidence of the superiority of conventional anticoagulation relative to surgical removal or antiplatelet agents is scarce, as are studies of independent predictors of systemic thromboembolism. The aims of this study were to investigate long-term clinical outcomes for LV thrombus, including the rate of systemic thromboembolism and complications of current therapeutics (conventional anticoagulation, operative treatment, antiplatelet agents) and to indentify independent predictors of systemic thromboembolism.

\section{Materials and Methods}

\section{Patient Population and Data Collection}

All patients with LV thrombus, diagnosed by two-dimensional echocardiography, cardiac magnetic resonance imaging (MRI) or coronary computed tomographic (CT) angiography were included as study subjects. From May 2003 to November 2011, we performed 75,936 two-dimensional transthoracic echocardiographies (TTEs), 1,100 cardiac MRIs and 9,338 coronary CT angiographies (CTAs). The respective imaging databases were screened for intra-cardiac thrombus; 69 patients were found with LV thrombus. After 7 of these patients, whose transesophageal echocardiography (TEE) confirmed no intra-cardiac thrombus, were excluded from this analysis, 62 patients remained as study patients (Fig. $\mathbf{1}$ ).

A comprehensive review of each patient's clinical data was performed using the electronic medical record system to identify baseline characteristics and medications at the time of LV thrombus diagnosis. Medical records were also evaluated for echocardiographic parameters, morphology of the LV thrombus in three imaging modalities, treatment of the LV thrombus, initial anticoagulation, details of the operative procedure, events of systemic thromboembolism, cardiac or all-cause mortality and complications of treatment including major or minor bleeding.

Decisions regarding the treatment strategy for LV thrombus were made by the patient's primary physi- 
cian. All patients who were anticoagulated with warfarin were evaluated by the Anticoagulation Service in our institution at least 1 or 2 times a month to maintain a stable prothrombin time (PT) international normalized ratio (INR) value between 2 to 3 . If the patients were treated with an antiplatelet agent only, the reasons for no anticoagulation were determined by medical record review and consultation with the patient's primary physician. An attempt was made to contact and interview, via telephone, all patients who were lost to follow-up. Except for 9 patients, including 4 deceased patients and 5 follow-up losses, all patients are currently being followed. This study was approved by the institutional review board.

\section{Imaging Modalities \\ Two-Dimensional Echocardiography}

Two-dimensional echocardiographic examinations were performed using three different commercially available systems (Vivid E9, GE Healthcare, Wilmington, MA, USA; Sonos 7500, Philips Medical Systems, Einthoven, The Netherlands; Sequoia C512, Siemens Medical Solutions, Erlangen, Germany) and standard techniques in accordance with the guidelines of the American Society of Echocardiography ${ }^{11}$. LV thrombus was defined as an echo-dense mass within the ventricular cavity with 1) a marked delineation toward the lumen and 2) a structural texture different from the myocardium and that 3) could be separated from the underlying endocardium by an endocardial lining; 4) was visible throughout the entire cardiac cycle; and 5) could be demonstrated in at least two different views as previously described ${ }^{8)}$. Any suspected diagnosis of LV thrombus with TTE was confirmed by TEE using the same equipment (Vivid E9; GE Healthcare). Thrombus shape was classified as pedunculated (with demonstration of pendulations apart from those mediated by myocardial contraction) or sessile; thrombus mobility was defined as mobile or mural. A mobile thrombus, including pedunculated or multiple thrombi, was categorized as a high-risk LV thrombus. The left ventricular ejection fraction and left atrial size were calculated by volumetric methods, which were measured in both apical 4-chamber and 2-chamber views. Every echocardiographic finding was confirmed at the time of examination by the staff of our institution, who specialize in cardiovascular imaging.

\section{Cardiac MRI and Coronary CT Angiography}

Cardiac MRI was performed with a 1.5 Tesla MR system (Philips Medical System). The imaging protocol included cine-MRI, T2-weighted imaging, early gadolinium enhancement and late gadolinium enhancement imaging. All subjects underwent coronary CTA with retrospective ECG gating on a 64 channel Multi-Detector CT scanner (Brilliance iCT; Philips Medical System, Boston, USA). Detailed imaging protocol of cardiac MRI and coronary CTA is presented in Supplementary Materials.

\section{Definitions and Outcome Analysis}

The conventional anticoagulation group was defined as patients who were prescribed warfarin, regardless of antiplatelet agent use. If the patient had undergone surgical removal of LV thrombus, the patient was classified into the operative treatment group, regardless of medication status. The antiplatelet agent group included patients who had received neither warfarin nor operative treatment for LV thrombus and who were taking one or more antiplatelet agents. In our study, many systemic thromboembolisms had occurred before treatment of LV thrombus began. Thus, we separated thromboembolic events as pre-treatment or post-treatment events. Embolic events that developed before the initiation of LV thrombus treatment were defined as pre-treatment. In contrast, embolic events that developed after the initiation of anticoagulation, antiplatelet agents or operative treatment were defined as post-treatment thromboembolism.

The primary outcome of the main analysis was the rate of post-treatment thromboembolism that included embolic cerebral infarction, transient ischemic attack and peripheral embolism. For cerebral infarction, the events were classified as embolic if the criteria, previously reported by Hart et al. ${ }^{12)}$, were met. Transient ischemic attack was defined as any focal neurologic deficit of sudden onset that lasted $<30 \mathrm{~min}$ and lacked abnormal findings on brain MRI. Peripheral thromboembolism was defined as a combination of signs and symptoms of end organ ischemic damage that was confirmed by conventional angiography or CTA.

The cause of death was classified as cardiac or non-cardiac, defined according to Academic Research Consortium definitions ${ }^{13}$. Bleeding events were defined according to the Thrombolysis in Myocardial Infarction (TIMI) criteria $^{14)}$. Major bleeding was defined as any intracranial hemorrhage, more than a $5 \mathrm{~g} / \mathrm{dL}$ decrease in the hemoglobin concentration or more than a $15 \%$ absolute decrease in the hematocrit.

Outcomes related to thrombus morphology and changes of the maximum size were also evaluated. Follow-up echocardiography was performed in 48 patients (77.42\%). Resolution of LV thrombus and the follow- 
up size of the thrombus were abstracted from the database. Thrombus resolution was strictly defined as complete resolution, that is, no evidence of LV thrombus on follow-up echocardiography. Width and thickness of the thrombus were recorded; maximum thrombus size was defined as the greatest value among all widths and thicknesses.

\section{Statistical Analysis}

Categorical variables are presented as numbers and relative frequencies (percentages) and were compared using the $\chi^{2}$ test or Fisher's exact test, as appropriate. Normally distributed continuous variables are expressed as the means and standard deviations, and between-group differences were analyzed using the independent sample $t$-test or the Mann-Whitney $U$ test as appropriate. The three treatment modalities were compared using the Kruskal-Wallis test for continuous variables and $\chi^{2}$ test for categorical variables. Pairwise comparisons between two groups were performed as post-hoc analysis using the Bonferroni corrected $p$ value. The change in LV thrombus size, before and after treatment, was evaluated with the Wilcoxon signed rank sum test. Kaplan-Meier analysis was used to calculate the cumulative incidence of the primary outcomes (post-treatment thromboembolism) and the log rank test or Breslow test was used to compare the differences in event-free survival among the groups, as appropriate.

A Cox proportional hazard regression model was used to evaluate the adjusted hazard ratio (HR) of each clinical variable and to identify independent predictors of pre-treatment or post-treatment systemic thromboembolism. Variables were included as covariates in multivariate analyses if they were distributed differently among the treatment groups, were associated with the primary outcome in univariate analyses or were generally accepted as potential confounders. The adjusted covariates are shown in Supplementary Table 1. Since there were differences in important baseline characteristics, such as the proportion of mobile or multiple thrombi and the maximum thrombus size among the three treatment groups, particularly between the anticoagulation group and antiplatelet agent group, we performed two 1:1 matched analyses without replacement (one compared the anticoagulation and operative treatment groups, the other compared the anticoagulation and antiplatelet agent groups) using a propensity score. The log-odds of the probability that a patient was treated with surgical removal or antiplatelet agents was modeled as a function of the confounders. A caliper width of 0.6 SDs was used because this value has been shown to elimi-
Supplementary Table 1. Independent Variables Analyzed using the Cox Proportional Hazard Regression Model

\begin{tabular}{|c|c|}
\hline Variables & Measure \\
\hline \multicolumn{2}{|l|}{ Baseline characteristics and risk factors } \\
\hline Age & Continuous \\
\hline $\operatorname{Sex}(M / F)$ & Nominal \\
\hline Hypertension & Nominal \\
\hline Diabetes mellitus & Nominal \\
\hline Current smoking & Nominal \\
\hline Dyslipidemia & Nominal \\
\hline Chronic renal failure & Nominal \\
\hline Atrial fibrillation (permanent or paroxysmal) & Nominal \\
\hline Malignancy & Nominal \\
\hline Previous myocardial infarction & Nominal \\
\hline Previous cerebrovascular accident & Nominal \\
\hline \multicolumn{2}{|l|}{ Underlying Heart Conditions } \\
\hline Cardiac arrest & Nominal \\
\hline Severe aortic stenosis & Nominal \\
\hline Ischemic CMP & Nominal \\
\hline Hypertrophic CMP & Nominal \\
\hline Stress-induced cardiomyopathy & Nominal \\
\hline Dilated CMP & Nominal \\
\hline \multicolumn{2}{|l|}{ Medications } \\
\hline Acetylsalicylic acid & Nominal \\
\hline Clopidogrel & Nominal \\
\hline Cilostazole & Nominal \\
\hline Triflusal & Nominal \\
\hline Warfarin & Nominal \\
\hline Beta-adrenergic receptor blockers & Nominal \\
\hline ACEI or ARB & Nominal \\
\hline Digoxin & Nominal \\
\hline Diuretics & Nominal \\
\hline Statin & Nominal \\
\hline Calcium-channel blocker & Nominal \\
\hline \multicolumn{2}{|l|}{ Echocardiographic parameters } \\
\hline LVEDD & Continuous \\
\hline LVESD & Continuous \\
\hline Ejection fraction & Continuous \\
\hline Left atrial size & Continuous \\
\hline Anteroapical aneurysm & Nominal \\
\hline \multicolumn{2}{|l|}{ Others } \\
\hline Thrombus mobility & Nominal \\
\hline Maximum size & Continuous \\
\hline Operation before embolism & Nominal \\
\hline Dor operation, aneurysmectomy, or thrombectomy & Nominal \\
\hline
\end{tabular}

* Data are expressed as the means \pm SD or as counts (\%).

Abbreviations: ACEI, angiotensin converting enzyme inhibitor; ARB, angiotensin receptor blocker; CMP, cardiomyopathy; LVEDD, left ventricular end-diastolic dimension; LVESD, left ventricular end-systolic dimension. 
Table 1. Baseline Characteristics of Patients with Left Ventricular Thrombus $(n=62)^{*}$

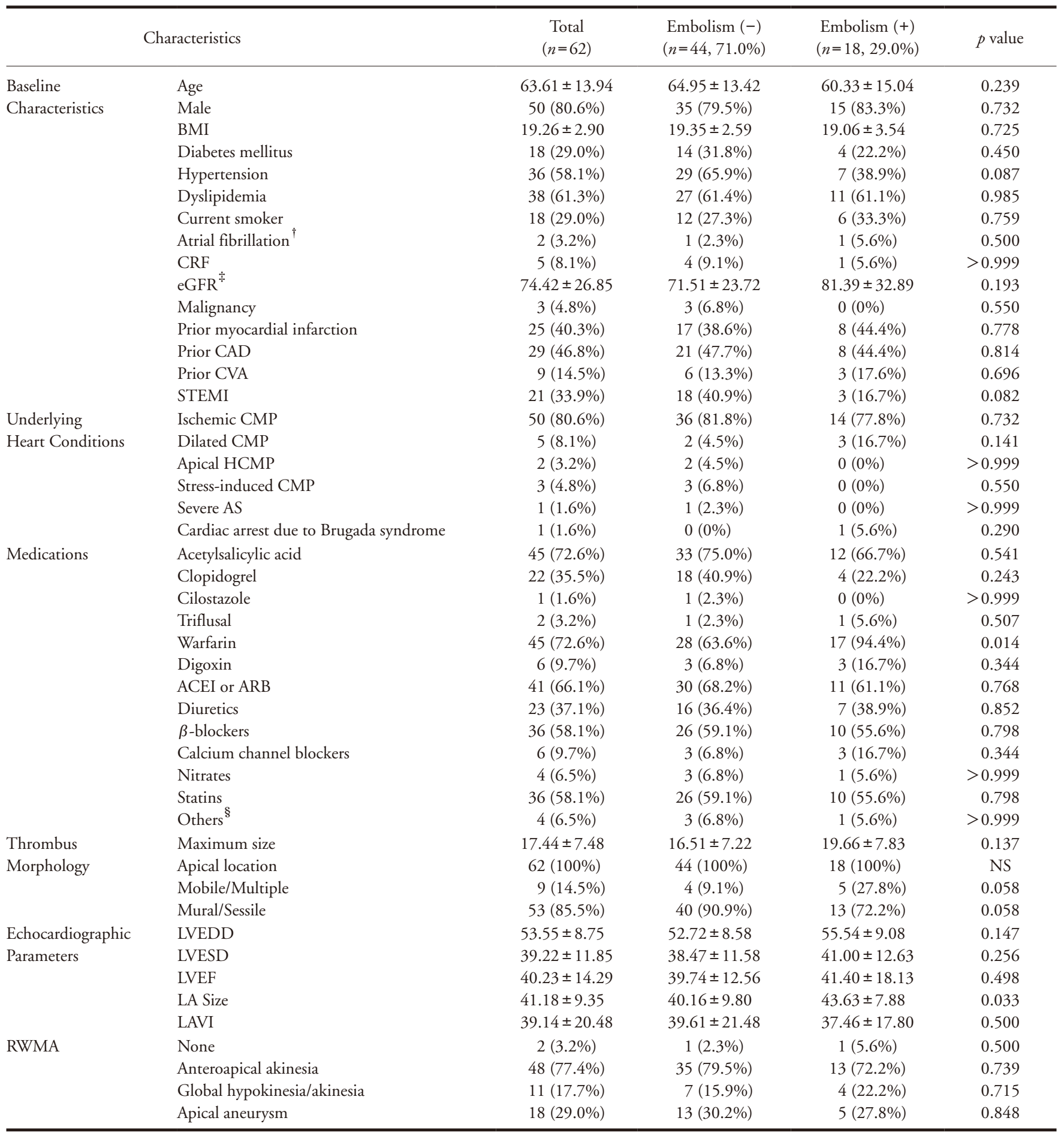

\footnotetext{
* Data are expressed as the means \pm SD or as counts (\%).

Atrial fibrillation included both permanent and paroxysmal atrial fibrillation.

\$Estimated glomerular filtration rate $\left(\mathrm{mL} / \mathrm{min} / 1.73 \mathrm{~m}^{2}\right)$ was calculated by MDRD (Modification of Diet in Renal Disease) equation.

${ }^{\S}$ Others included coronary vasodilators (nicorandil) or metabolic agents (vastinan).

Abbreviations: AS, aortic stenosis; ACEI, angiotensin converting enzyme inhibitor; ARB, angiotensin receptor blocker; CAD, coronary artery disease; CMP, cardiomyopathy; CRF, chronic renal failure; CVA, cerebrovascular accident; eGFR, estimated glomerular filtration rate; HCMP, hypertrophic cardiomyopathy; LA, left atrium; LAVI, left atrium volume index; LVEDD, left ventricular end-diastolic dimension; LVESD, left ventricular end-systolic dimension; LVEF, left ventricular ejection fraction; RWMA, regional wall motion abnormality; STEMI, ST segment elevation myocardial infarction.
} 
Table 2. Diagnostic Modalities of 62 Cases of Left Ventricular Thrombus

\begin{tabular}{lccc}
\hline $\begin{array}{c}\text { Diagnostic } \\
\text { Modality }\end{array}$ & $\begin{array}{c}\text { Number of } \\
\text { Examinations }\end{array}$ & $\begin{array}{c}\text { Patients with } \\
(+) \text { result }\end{array}$ & $\begin{array}{c}\text { Detection } \\
\text { Rate* }\end{array}$ \\
\hline TTE & 61 & 48 & $78.7 \%$ \\
MRI & 13 & 13 & $100 \%$ \\
CT angiography & 12 & 12 & $100 \%$ \\
\hline
\end{tabular}

* Detection rate (\%) was defined as the proportion of positive results per number of diagnostic examinations performed.

Abbreviations: CT, computed tomography; MRI, magnetic resonance imaging, TTE, transthoracic echocardiography.

nate almost $90 \%$ of the bias in the observed confounders ${ }^{15}$. All probability values were two-sided and $p$-values $<0.05$ were considered statistically significant. In case of Bonferroni correction, $p$-values $<0.017$ were considered statistically significant. The statistical package SPSS, version 18.0 (SPSS Inc., Chicago, IL, USA) and GraphPad Prism, version 5 (GraphPad Software Inc., La Jolla, CA, USA) were used for statistical analyses.

\section{Results}

\section{Patient Population and Baseline Characteristics}

Among 86,374 patients who underwent twodimensional echocardiography, cardiac MRI, or coronary CTA from May 2003 to November 2011, 62 patients had documented LV thrombus (Fig. 1). Mean age was $63.61 \pm 13.94$ years, the majority were male $(80.6 \%)$ and had ischemic heart disease (80.6\%) including acute MI (Table 1). Twenty-one patients (33.9\%) were admitted due to acute ST segment elevation MI (STEMI) that was treated with primary percutaneous coronary intervention within 90 minutes of door-to-balloon time (19 patients, $90.5 \%$ ) or thrombolysis within 30 minutes of door-to-needle time (2 patients, 9.5\%). All patients with STEMI had anterior wall myocardial infarction.

Eighteen of 62 patients (29\%) developed systemic thromboembolism, with pre-treatment and post-treatment thromboembolism combined. There were no significant differences in baseline characteristics or medication history between patients with or without thromboembolism except for warfarin. Most patients $(72.6 \%)$ were taking low-dose acetylsalicylic acid $(100 \mathrm{mg} /$ day) and $35.5 \%$ of patients were taking clopidogrel.

None of the study patients had hypo- or hyperthyroidism or a medical or familial history of congenital thrombophilic disorders, for example, protein $\mathrm{C}, \mathrm{S}$

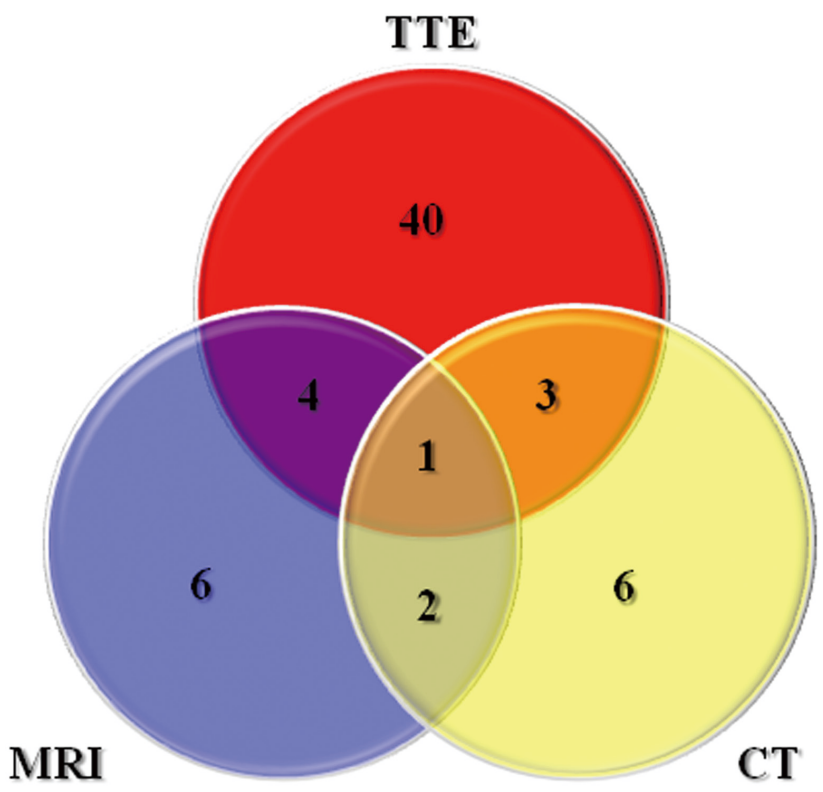

Supplementary Fig. 1. Diagnostic Modalities for Left Ventricular Thrombus.

This Venn diagram depicts the diagnostic modality that definitely diagnosed LV thrombus. In the study population, 61 patients underwent trans-thoracic echocardiography (TTE). Among them, LV thrombus was found in only 48 patients by TTE. Thirteen of the 14 patients, who were diagnosed with LV thrombus through cardiac MRI or coronary CT angiography, did not show LV thrombus on their TTE.

or antithrombin deficiency or antiphospholipid antibody syndrome. In addition, no patient had both LV thrombus and ventricular non-compaction, which has been associated with systemic thromboembolism ${ }^{16)}$.

\section{Thrombus Characteristics and Echocardiographic Parameters}

All of the LV thrombi were located in the cardiac apex and most had mural attachment and sessile morphology (53 patients, 85.5\%) (Table 1). High-risk thrombi (mobile thrombi including pedunculated or multiple thrombi) were more frequent in patients with thromboembolism $(9.1 \%$ vs. $27.8 \%, p=0.058)$. Patients with or without thromboembolism had similar echocardiographic parameters, excepting that the LA size was larger in patients with thromboembolism (Table 1). Using the aforementioned analysis, several variables, including thrombus mobility, maximum thrombus size, echocardiographic parameters and medication history, were selected as covariates for multivariate analysis to elucidate independent predictors of systemic thromboembolism (Supplementary Table 1). 
Table 3. Comparison of Treatment Groups for Left Ventricular Thrombus*

\begin{tabular}{|c|c|c|c|c|}
\hline & $\begin{array}{l}\text { Anticoagulation } \\
(n=42,67.7 \%)\end{array}$ & $\begin{array}{l}\text { Operative Treatment } \\
\quad(n=8,12.9 \%)\end{array}$ & $\begin{array}{l}\text { Antiplatelet Agent } \\
(n=12,19.4 \%)\end{array}$ & $p$ value \\
\hline Interval to treatment (days) & 0 (IQR 0-13.75) & $5.0(\mathrm{IQR} 2-11)$ & 0 (IQR -4-0) & 0.924 \\
\hline \multicolumn{5}{|l|}{ Baseline Characteristics } \\
\hline Age & $63.90 \pm 14.07$ & $60.50 \pm 14.56$ & $64.67 \pm 14.04$ & 0.790 \\
\hline Diabetes mellitus & $11(26.2 \%)$ & $3(37.5 \%)$ & $4(33.3 \%)$ & 0.759 \\
\hline Hypertension & $24(57.1 \%)$ & $4(50.0 \%)$ & $8(66.7 \%)$ & 0.743 \\
\hline Dyslipidemia & $27(64.3 \%)$ & $5(62.5 \%)$ & $6(50.0 \%)$ & 0.667 \\
\hline Current smoker & $13(31.0 \%)$ & $3(37.5 \%)$ & $2(16.7 \%)$ & 0.537 \\
\hline Atrial fibrillation $^{\dagger}$ & $2(4.8 \%)$ & $0(0 \%)$ & $0(0 \%)$ & 0.611 \\
\hline Prior $\mathrm{CAD}$ & $17(40.5 \%)$ & $4(50.0 \%)$ & $8(66.7 \%)$ & 0.271 \\
\hline Prior CVA & $4(9.5 \%)$ & $1(12.5 \%)$ & $4(33.3 \%)$ & 0.117 \\
\hline STEMI & $15(35.7 \%)$ & $2(25.0 \%)$ & $4(33.3 \%)$ & 0.835 \\
\hline \multicolumn{5}{|l|}{ Underlying Heart Condition } \\
\hline Ischemic CMP & $32(76.2 \%)$ & $7(87.5 \%)$ & $11(91.7 \%)$ & 0.426 \\
\hline Dilated CMP & $5(11.9 \%)$ & $0(0 \%)$ & $0(0 \%)$ & 0.274 \\
\hline Apical HCMP & $2(4.8 \%)$ & $0(0 \%)$ & $0(0 \%)$ & 0.611 \\
\hline Stress-induced CMP & $2(4.8 \%)$ & $0(0 \%)$ & $1(8.3 \%)$ & 0.696 \\
\hline Severe AS & $0(0 \%)$ & $1(12.5 \%)$ & $0(0 \%)$ & 0.032 \\
\hline Cardiac arrest due to Brugada syndrome & $1(2.4 \%)$ & $0(0 \%)$ & $0(0 \%)$ & 0.785 \\
\hline
\end{tabular}

* Data are expressed as counts (\%), unless otherwise indicated. Days are presented as the median value and interquatile range.

Atrial fibrillation included both permanent and paroxysmal atrial fibrillation.

* Treatment duration in operative treatment group defined as postoperative duration in days.

${ }^{\S}$ Estimated glomerular filtration rate $\left(\mathrm{mL} / \mathrm{min} / 1.73 \mathrm{~m}^{2}\right)$ was calculated by MDRD (Modification of Diet in Renal Disease) equation.

Abbreviations: AS, aortic stenosis; CAD, coronary artery disease; CMP, cardiomyopathy; CRF, chronic renal failure; CVA, cerebrovascular accident; eGFR, estimated glomerular filtration rate; HCMP, hypertrophic cardiomyopathy; IQR, interquatile range; STEMI, ST segment elevation myocardial infarction.

\section{Diagnostic Modalities}

TTE was performed in 61 of the 62 study patients; however, LV thrombus was diagnosed only in 48 patients $(78.7 \%)$ (Table 2 ). In the remaining 13 patients, LV thrombus was recognized by cardiac MRI or coronary CTA, as shown in Supplementary Fig. 1.

\section{Treatment Groups for the LV Thrombus}

Each patient was treated for LV thrombus with one of three treatment options according to the primary physician's decision; $42(67.7 \%)$ were treated with conventional anticoagulation, $8(12.9 \%)$ with operative treatment and $12(19.4 \%)$ only with antiplatelet agents (Table 3). There were no significant differences in baseline characteristics except for 1 patient with severe aortic valve stenosis in the operative treatment group.
In the anticoagulation group, adequate ranges of PT INR were maintained and the mean PT INR value was $2.75 \pm 0.43$ during the treatment period (median 327 days). In 18 (42.9\%) patients, anticoagulation was discontinued due to complete resolution of thrombus, based on follow-up echocardiography, (11 patients, 61.1\%), bleeding (major bleeding: 1 patients, $11.1 \%$; minor bleeding: 3 patients, $16.7 \%)$, death (2 patients including 1 death due to major bleeding, $11.1 \%)$ and refusal by the patient (1 patient, 5.6\%). None of the 11 patients who discontinued warfarin after TEE showed complete resolution of LV thrombus had post-treatment thromboembolism. Follow-up TEE did not detect recurrence of LV thrombus when performed in 4 patients after resolution of the thrombus (median duration of follow-up echocardiography: 456 days (IQR 193.75-888.50 days). 
Supplementary Table 2. Detailed Descriptions of Operative Treatment of LV Thrombus

\begin{tabular}{|c|c|c|c|c|c|}
\hline Patient & $\begin{array}{l}\text { Indication and pre-operative } \\
\text { condition }\end{array}$ & OP & OP type & Complications & $\begin{array}{l}\text { Discharge date } \\
\text { (Postoperative) }\end{array}$ \\
\hline $\mathrm{M} / 78$ & $\begin{array}{l}\text { 3VD with LV thrombus, } \\
\text { Ambulatory }\end{array}$ & $\mathrm{CABG}+$ Dor & Elective & None & 9 days \\
\hline $\mathrm{M} / 47$ & $\begin{array}{l}\text { 3VD with LV thrombus, } \\
\text { Ambulatory }\end{array}$ & CABG + Dor & Elective & None & 15 days \\
\hline $\mathrm{F} / 83$ & $\begin{array}{l}\text { 3VD with LV thrombus, } \\
\text { Cardiogenic shock under IABP }\end{array}$ & $\begin{array}{l}\text { CABG + } \\
\text { Thrombectomy }\end{array}$ & Emergency & None & 10 days \\
\hline $\mathrm{M} / 68$ & $\begin{array}{l}\text { 3VD with LV thrombus, } \\
\text { Ambulatory }\end{array}$ & $\begin{array}{l}\text { CABG + } \\
\text { Thrombectomy }\end{array}$ & Elective & None & 4 days \\
\hline $\mathrm{M} / 41$ & $\begin{array}{l}\text { Severe AS with LV thrombus, } \\
\text { Cardiac arrest under ECMO }\end{array}$ & $\begin{array}{l}\text { Bentall OP + } \\
\text { Thrombectomy }\end{array}$ & Emergency & $\begin{array}{l}\text { ECMO wound } \\
\text { infection }\end{array}$ & 49 days \\
\hline $\mathrm{M} / 54$ & $\begin{array}{l}\text { 3VD with LV thrombus, Cardiac } \\
\text { arrest under ECMO }\end{array}$ & CABG + Dor & Elective & None & 18 days \\
\hline $\mathrm{M} / 57$ & $\begin{array}{l}\text { 3VD with LV thrombus (High- } \\
\text { risk thrombus with small embolic } \\
\text { stroke), Bed-ridden }\end{array}$ & CABG + Dor & Urgent & $\begin{array}{l}\text { RITA harvest site } \\
\text { bleeding }^{*}\end{array}$ & 15 days \\
\hline $\mathrm{M} / 57$ & $\begin{array}{l}3 \mathrm{VD} \text { with LV thrombus (High- } \\
\text { risk thrombus with multiple } \\
\text { embolic strokes and hemorrhagic } \\
\text { conversion }^{\dagger} \text { ), Bed-ridden }\end{array}$ & $\begin{array}{c}\text { CABG + Dor + } \\
\text { Craniotomy and } \\
\text { hematoma evacuation }\end{array}$ & Emergency & None & $\begin{array}{l}\text { Admission for } \\
\text { postoperative } \\
\text { rehabilitation }\end{array}$ \\
\hline
\end{tabular}

\footnotetext{
*This patient developed postoperative hemothorax; re-do sternotomy found bleeding at the RITA harvest site. The bleeding focus was successfully controlled. This event counted as a TIMI major bleeding event.

${ }^{\dagger}$ This patient developed hemorrhagic conversion of an embolic cerebral infarction during infusion of unfractionated heparin preoperatively. Thus, we did not count this event as a TIMI major bleeding event in the operative treatment group.

Abbreviations: AS, aortic stenosis; CABG, coronary artery bypass grafting; Dor, Dor operation; ECMO, extracorporeal membrane oxygenation; IABP, intra-aortic balloon pump; LV, left ventricle; OP, operation; RITA, right internal thoracic artery; $3 \mathrm{VD}$, three-vessel coronary artery disease.
}

All but one patient in the operative treatment group were diagnosed with 3-vessel disease, which required coronary artery bypass grafting (CABG). One patient had been diagnosed with severe aortic stenosis due to a bicuspid aortic valve (Supplementary Table 2). The median interval from thrombus detection to operation was 5 days (Table 3).

The 12 patients that were treated only with antiplatelet agents had at least one reason that precluded anticoagulation (Supplementary Fig. 2). The most frequent reason for preclusion was a high risk for bleeding (7 patients).

\section{Thrombus Outcomes}

The frequency of high-risk thrombi did not differ among the treatment groups; however, the maximum thrombus size was significantly smaller in the antiplatelet agent group (Table 4). The relative size decrease was significantly greater in the anticoagulation and operative treatment groups than in the anti- platelet agent group (Table $\mathbf{4}$ and Fig. 2A). Moreover, follow-up echocardiography showed complete resolution of thrombus in all patients in the operative treatment group (Fig. 2B). In the antiplatelet agent group, follow-up size of the thrombus was not significantly different from the initial size (Fig. 2A).

\section{Clinical Outcomes}

Ten $(55.0 \%)$ of the 18 thromboembolism events occurred before the treatment began (pre-treatment thromboembolism). Post-treatment thromboembolism developed in $17.1 \%$ of the anticoagulation group, $0 \%$ of the operative treatment group and $8.3 \%$ of the antiplatelet agent group, without statistically significant differences (Table 4). Thromboembolism-free survival of the treatment groups, depicted in Fig. 3A, showed a tendency towards longer survival in the operative and antiplatelet agent groups than in the anticoagulation group, which was not significantly different. During the median follow-up of 24 months, 


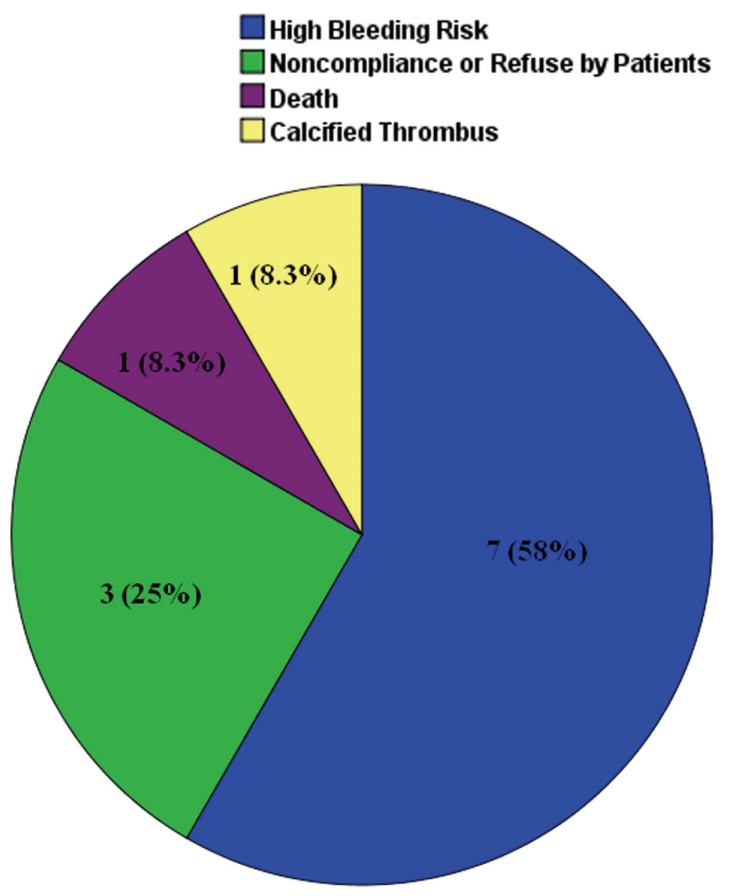

Supplementary Fig. 2. Reasons for not using Anticoagulation in the Antiplatelet Agent Group.

Twelve patients were treated with one or more antiplatelet agents only. The reason that precluded anticoagulation with warfarin is depicted. Seven patients were considered at high risk for bleeding for the following reasons: recurrent gastrointestinal tract bleeding due to benign peptic ulcer disease or inflammatory bowel disease, 4 patients; receiving intraocular treatment for medically intractable glaucoma, 1 patient and liver cirrhosis Child class B to C with PT prolongation, 2 patients. Three patients, who had advanced dementia and lacked care-givers, were considered to be unable to keep comply with the details of warfarin anticoagulation and required regular follow-up.

no post-treatment thromboembolism event occurred in the operative treatment group; in contrast, such events occurred in the anticoagulation group and antiplatelet agent group.

Major and minor bleeding events developed more frequently in the anticoagulation group than in the operative treatment group; however, one patient in the operative treatment group developed postoperative bleeding from a right internal thoracic artery harvesting site (Table 4). Notably, the two major bleeding events in the anticoagulation group consisted of intracranial bleeding that resulted in permanent neurologic sequelae and massive gastrointestinal tract bleeding that resulted in death. All three minor bleeding events occurred in the anticoagulation group. All the bleeding events precluded further maintenance of anticoagulation.

There were 4 deaths (Table 4 ). In the anticoagu- lation group there were 2 cardiac deaths (one cardiogenic shock due to non-ST segment elevation myocardial infarction and one sudden cardiac death due to ventricular tachycardia) and one death due to massive gastrointestinal bleeding. One patient in the antiplatelet agent group died of septic shock.

\section{Clinical Outcomes in Propensity Score Matched Groups}

Post-treatment thromboembolism showed a tendency towards a lower rate in the operative and antiplatelet agent groups than in the anticoagulation group (Fig. 3A); however, the frequency of high-risk thrombi and thrombus maximum size were lower in the antiplatelet agent group. In addition, the treatment groups differed in baseline characteristics including medications and thrombus profiles (Table 3 and 4). Because of such differences, we performed propensity score matching, which yielded 8 pairs for each comparison, anticoagulation versus operative treatment and anticoagulation versus antiplatelet agents. Matching produced more balanced groups, particularly with respect to medications and thrombus profiles (Supplementary Table 3 and 4).

In this comparison of the anticoagulation versus operative treatment groups, two post-treatment thromboembolism events occurred, both in the anticoagulation group (Supplementary Table 3). In addition, survival curves showed more prominent differences in the event-free survival (Fig. 3B) compared with that of unmatched analysis (Fig. 3A).

In contrast, one patient in each group suffered post-treatment thromboembolism in the matched pairs of the anticoagulation and antiplatelet agent groups (Supplementary Table 4). The tendency towards lower post-treatment thromboembolism in the antiplatelet agent group in the survival curve, which was found in the unmatched analysis (Fig. 3A), disappeared in the propensity score-matched analysis (Fig. 3C).

\section{Clinical Outcomes According to the Underlying Heart Condition}

The treatment groups were inhomogeneous with respect to the underlying heart condition, and ischemic etiology was found in 32 (76.2\%), 7 (87.5\%) and $11(91.7 \%)$ of patients treated with anticoagulation, operative treatment and antiplatelet therapy, respectively (Table 3). Among patients with non-ischemic etiology, 10 patients were treated with anticoagulation, 1 patient with operation, and 1 patient with antiplatelet therapy. Among all study subjects, only 5 (8.1\%) patients had DCMP; all were treated with anticoagulation. Therefore, we performed further 
Table 4. Clinical Outcomes According to Treatment Group*

\begin{tabular}{|c|c|c|c|c|}
\hline Outcome & $\begin{array}{l}\text { Anticoagulation } \\
(n=42,67.7 \%)\end{array}$ & $\begin{array}{l}\text { Operative Treatment } \\
\quad(n=8,12.9 \%)\end{array}$ & $\begin{array}{l}\text { Antiplatelet Agent } \\
(n=12,19.4 \%)\end{array}$ & $p$ value \\
\hline \multicolumn{5}{|l|}{ Thrombus Morphology } \\
\hline High-risk thrombus ${ }^{\dagger}$ & $6(14.3 \%)$ & $2(25.0 \%)$ & $1(8.3 \%)$ & 0.648 \\
\hline Maximum size & $18.37 \pm 7.31$ & $18.36 \pm 5.75$ & $13.23 \pm 8.32$ & 0.019 \\
\hline \multicolumn{5}{|l|}{ Thrombus Outcomes } \\
\hline Follow-up echo & $32(76.2 \%)$ & $8(100.0 \%)$ & $8(66.7 \%)$ & 0.193 \\
\hline Interval to echo & 354.0 (IQR 55.0-790.5) & 55.0 (IQR 13.0-254.0) & 392.5 (IQR 184.8-1159.0) & 0.068 \\
\hline Resolution & $21(65.6 \%)$ & $8(100.0 \%)$ & $2(25.0 \%)$ & 0.006 \\
\hline Follow-up size & $6.11 \pm 9.87$ & 0.00 & $11.56 \pm 11.44$ & 0.018 \\
\hline Size decrease $(\mathrm{mm})$ & $-12.16 \pm 11.30$ & $-18.36 \pm 5.75$ & $-2.13 \pm 5.56$ & 0.007 \\
\hline Size decrease (\%) & $-67.69 \pm 49.76 \%$ & $-100.0 \%$ & $-12.00 \pm 41.82 \%$ & 0.002 \\
\hline \multicolumn{5}{|l|}{ Clinical Outcomes } \\
\hline Any embolism & $15(35.7 \%)$ & $2(25.0 \%)$ & $1(0 \%)$ & 0.202 \\
\hline Pre-treatment & $8(19.5 \%)$ & $2(25.0 \%)$ & $0(0 \%)$ & 0.152 \\
\hline Post-treatment & $7(17.1 \%)$ & $0(0 \%)$ & $1(8.3 \%)$ & 0.618 \\
\hline CVA & $11(26.2 \%)$ & $2(25.0 \%)$ & $1(8.3 \%)$ & 0.422 \\
\hline TIA & $2(18.2 \%)$ & $0(0 \%)$ & $0(0 \%)$ & $>0.999$ \\
\hline Stroke & $9(81.8 \%)$ & $2(100 \%)$ & $1(100 \%)$ & $>0.999$ \\
\hline Neurologic sequela & $7(63.6 \%)$ & $2(100 \%)$ & $1(100 \%)$ & 0.670 \\
\hline Peripheral embolism & $4(9.5 \%)$ & $0(0 \%)$ & $0(0 \%)$ & 0.753 \\
\hline Bleeding event ${ }^{\S}$ & $5(11.9 \%)$ & $1(12.5 \%)^{9}$ & $0(0 \%)$ & 0.539 \\
\hline Major & $2(4.8 \%)^{\#}$ & $1(12.5 \%)^{9}$ & $0(0 \%)$ & 0.423 \\
\hline Minor & $3(7.1 \%)$ & $0(0 \%)$ & $0(0 \%)$ & $>0.999$ \\
\hline Cardiac death & $2(4.8 \%)$ & $0(0 \%)$ & $0(0 \%)$ & $>0.999$ \\
\hline Death due to bleeding & $1(2.4 \%)$ & $0(0 \%)$ & $0(0 \%)$ & $>0.999$ \\
\hline All Cause death & $3(7.1 \%)$ & $0(0 \%)$ & $1(8.3 \%)$ & $>0.999$ \\
\hline
\end{tabular}

* Data are expressed as the means \pm SD or as counts (\%).

${ }^{\dagger}$ High-risk thrombus was defined as either a mobile thrombus, including pedunculated thrombus, or multiple left ventricular thrombi.

" Interval to follow-up echocardiography, data are expressed as median and interquatile range.

${ }^{\S}$ Bleeding events were defined according to the Thrombolysis in Myocardial Infarction (TIMI) criteria. Major bleeding was defined as any intracranial hemorrhage, more than a $5 \mathrm{~g} / \mathrm{dL}$ decrease in the hemoglobin concentration or more than a $15 \%$ absolute decrease in the hematocrit.

" One patient in the operative treatment group developed postoperative bleeding from the right internal thoracic artery harvest site. The patient was successfully treated with re-do sternotomy and bleeding control.

\# These two major bleeding events included one death due to massive hematemesis and subsequent hypovolemic shock.

Abbreviations: Echo, echocardiography; IQR interquatile range; TIA, transient ischemic attack.

analyses according to the underlying etiology, ischemic versus non-ischemic and DCMP versus no DCMP (Supplementary Table 5).

Post-treatment thromboembolism developed in 2 patients (40\%) with DCMP. In univariate analysis, DCMP was associated with a 5.6-fold increased risk for post-treatment thromboembolism (OR, 5.67; 95\% CI $0.78-41.01 ; p=0.059)$. After adjustment for potential confounders, DCMP remained a strong and significant independent predictor of post-treatment thromboembolism (Table 5). In contrast, ischemic cardiomyopathy was not associated with post-treatment thromboembolism in univariate (OR, 0.68; $95 \% \mathrm{CI}, 0.12-3.89 ; p=0.665)$ or in multivariate anal- yses (OR, 0.05; 95\% CI, 0.00-1227.12; $p=0.977)$.

\section{Independent Predictors of Thromboembolism}

Using a Cox proportional hazard regression model with the aforementioned multiple covariates (Supplementary Table 1), independent predictors of pre-treatment thromboembolism were cardiac arrest and mobile or multiple thrombi. Independent predictors of post-treatment thromboembolism were female gender, a previous cerebrovascular event, DCMP and large left ventricular end-diastolic diameter (LVEDD) (Table 5). Treatment modalities (anticoagulation, operative treatment, or antiplatelet agents) were not independent predictors of systemic thromboembolism. 


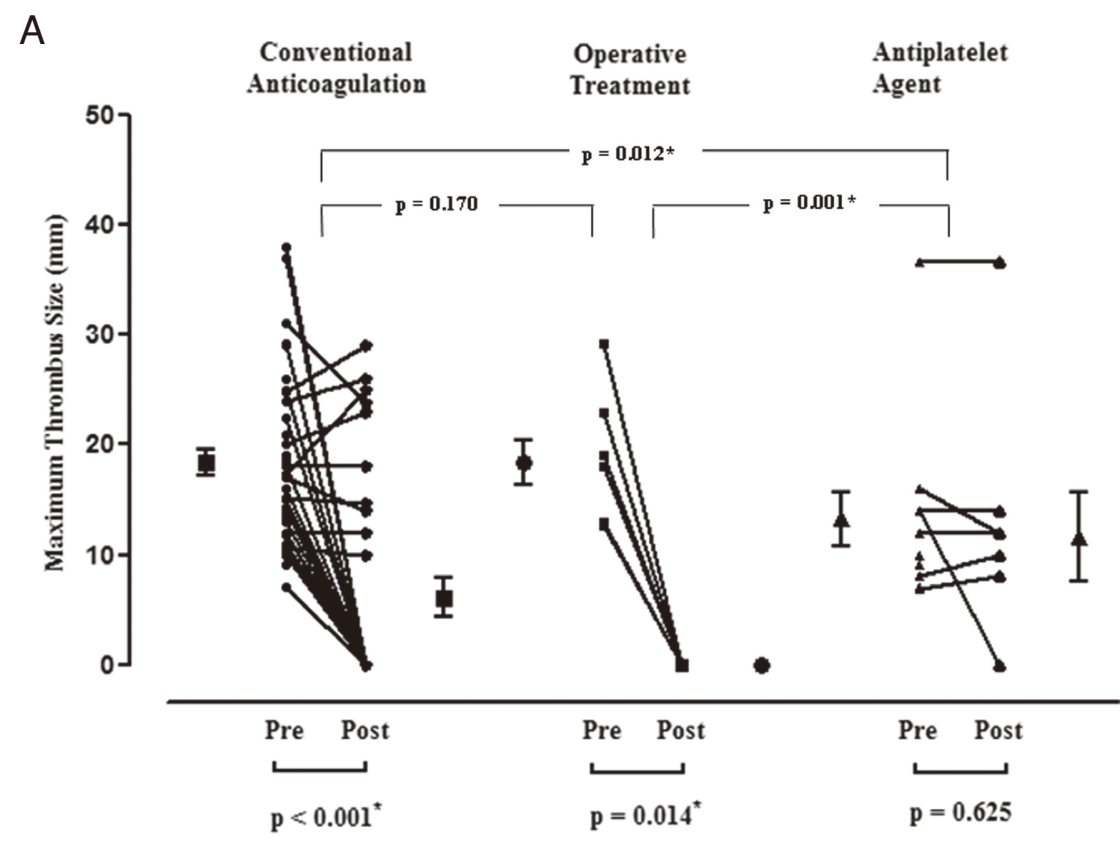

B

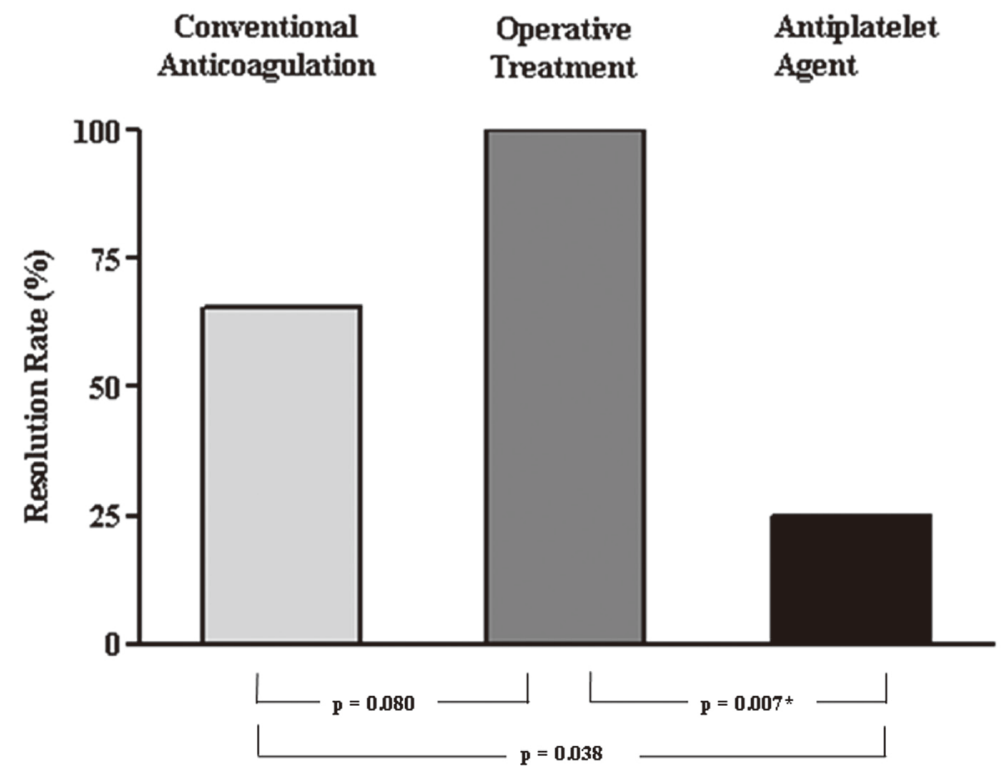

Fig. 2. Changes of LV Thrombus Size and Resolution Rate According to the Treatment Groups.

A) Changes of LV thrombus size $(\mathrm{mm})$. B) Thrombus resolution rate based on follow-up echocardiography. The resolution rate was significantly different among the three groups. The resolution rate was significantly higher in the operative treatment group than in the antiplatelet agent group $(100.0 \%$ vs. $25.0 \%$, Bonferroni corrected $p=0.007)$. However, there was no significant difference in the relative size change and resolution rate between anticoagulation group and operative treatment group in the post-hoc analysis. The results of Wilcoxon signed rank sum test for the analyses of the change of LV thrombus size before and after the treatment are presented. Post-hoc analyses with Bonferroni corrected $p$ value are also presented. Asterisk denotes a statistically significant $p$ value.

Univariate analysis of the subgroup with nonischemic etiology $(n=12)$ without indications for open heart surgery, found that LVEDD and the proportion of mobile or multiple thrombi were greater in those with post-treatment thromboembolism, with marginal statistical significance (Supplementary Table 6); however, we could not build a model for multivariate analysis in this subgroup due its small size. 


\section{A}

Thromboembolic Event Free Survival in Each Treatment Group

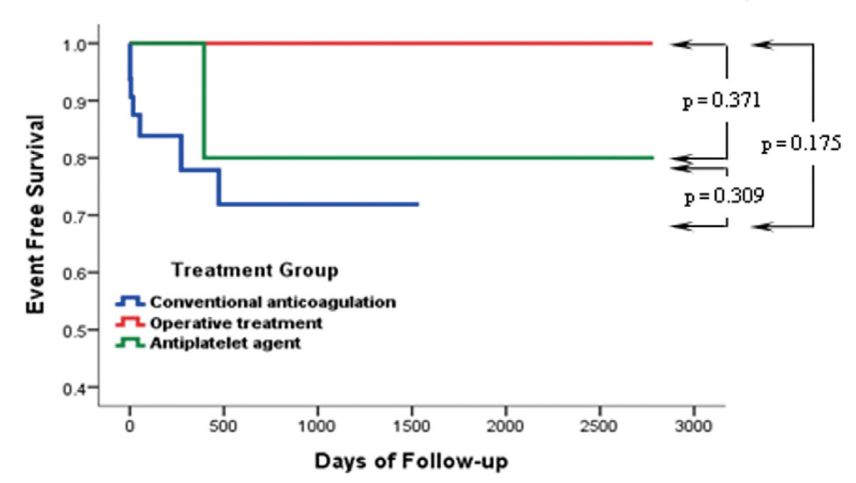

$\begin{array}{lllllll}\text { Conventional } & 38 & 12 & 10 & 1 & & \\ \text { Asticoagulation } & 7 & 0 & 0 & 0 & & \\ \text { Operative } & 8 & 5 & 3 & 3 & 1 & 1 \\ \text { Treatment } & 0 & 0 & 0 & 0 & 0 & 0 \\ \text { Antimlatelet } & 12 & 6 & 4 & 2 & 1 & 1 \\ \text { Agent } & 0 & 1 & 0 & 0 & 0 & 0\end{array}$

B Thromboembolism Event Free Survival in Propensity Score Matched Group

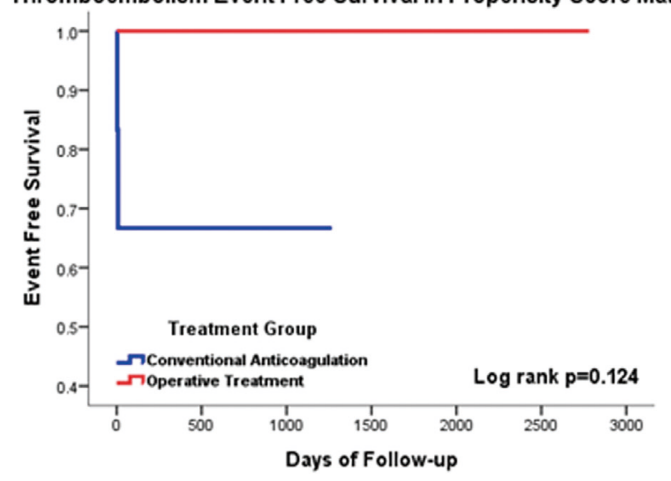

1

$\begin{array}{llll}\text { Conventional } & 8 & 1 & 1 \\ \text { Anticosgulation } & 2 & 0 & 0 \\ \text { Operative } & 8 & 5 & 3 \\ \text { Treatinest } & 0 & 0 & 0\end{array}$

Fig. 3. Kaplan-Meier Curves for Thromboembolic Event Free Survival According to the Treatment Groups (Post-treatment Embolism Only).

Clinical outcomes analyses were performed only with post-treatment embolism. A) Kaplan-Meier Curves show a comparison of event-free survival among the three treatment groups. Log rank $p$ values are presented. B) Thromboembolic event-free survival in propensity score matched pairs, comparison between anticoagulation and operative treatment groups. C) Thromboembolic event-free survival in propensity score matched pairs, comparison between anticoagulation and antiplatelet agent groups. Because the survival curves crossed, the Breslow $p$ value was determined.

\section{Discussion}

The current study measured the long-term outcomes of treatment strategies during a median followup of 24 months. The overall risk of systemic thromboembolism during 2 years was $29.0 \%$. Over one-half of the systemic thromboembolisms $(55.0 \%)$ occurred before the detection of LV thrombus (pre-treatment thromboembolisms). The rate of post-treatment thromboembolism was not significantly different among the three treatment groups.
The operative treatment group had no post-treatment thromboembolisms and the highest resolution rate and decrease of LV thrombus size. The conventional anticoagulation group had the highest rate of post-treatment embolism ( 7 of 8 events, $87.5 \%$ occurred in this group), despite a larger decrease in thrombus size than in the antiplatelet agent group. Notably, post-treatment thromboembolism even occurred during adequate maintenance of the target PT INR. 
Supplementary Table 3. Propensity Score Matching between the Anticoagulation and Operative Treatment Groups*

\begin{tabular}{|c|c|c|c|}
\hline & Anticoagulation $(n=8)$ & Operative Treatment $(n=8)$ & $p$ value \\
\hline \multicolumn{4}{|l|}{ Medications } \\
\hline Acetylsalicylic acid & $6(75.0 \%)$ & $7(87.5 \%)$ & $>0.999$ \\
\hline Clopidogrel & $2(25.0 \%)$ & $2(25.0 \%)$ & $>0.999$ \\
\hline Dual antiplatelet agents (Aspirin and Clopidogrel) & $2(25.0 \%)$ & $2(25.0 \%)$ & $>0.999$ \\
\hline Warfarin & $8(100.0 \%)$ & $3(37.5 \%)$ & 0.315 \\
\hline \multicolumn{4}{|l|}{ Thrombus Morphology } \\
\hline High-risk thrombus $^{\dagger}$ & $3(37.5 \%)$ & $2(25.0 \%)$ & $>0.999$ \\
\hline Maximum size & $19.88 \pm 9.72$ & $18.36 \pm 5.75$ & 0.916 \\
\hline \multicolumn{4}{|l|}{ Thrombus Outcomes } \\
\hline Follow-up echo & $6(75.0 \%)$ & $8(100.0 \%)$ & 0.467 \\
\hline Resolution & $3(50.0 \%)$ & $8(100.0 \%)$ & 0.055 \\
\hline Follow-up size & $10.47 \pm 12.08$ & 0.0 & 0.031 \\
\hline \multicolumn{4}{|l|}{ Clinical Outcomes } \\
\hline Post-treatment & $2(25.0 \%)$ & $0(0.0 \%)$ & 0.467 \\
\hline CVA & $0(0 \%)$ & $1(12.5 \%)$ & $>0.999$ \\
\hline Peripheral embolism & $1(12.5 \%)$ & $0(0 \%)$ & $>0.999$ \\
\hline Bleeding event ${ }^{*}$ & $2(25.0 \%)$ & $1(12.5 \%)$ & $>0.999$ \\
\hline Minor & $1(12.5 \%)$ & $0(0 \%)$ & $>0.999$ \\
\hline Major & $1(12.5 \%)$ & $1(12.5 \%)$ & $>0.999$ \\
\hline
\end{tabular}

* Data are expressed as the means \pm SD or as counts (\%).

${ }^{\dagger}$ High-risk thrombus was defined as mobile or multiple left ventricular thrombi.

" Bleeding events were defined according to the Thrombolysis in Myocardial Infarction (TIMI) criteria. Major bleeding was defined as any intracranial hemorrhage, more than a $5 \mathrm{~g} / \mathrm{dL}$ decrease in the hemoglobin concentration or more than a $15 \%$ absolute decrease in the hematocrit.

Abbreviations: CVA, cerebrovascular accident; echo, echocardiography.

\section{Embolic Risk of Conventional Anticoagulation}

Regarding the efficacy of anticoagulation, two previous meta-analyses found that the relative risk of embolism in anticoagulated patients with LV thrombus after myocardial infarction was 0.3 (95\% CI 0.1 $0.5)$ and $0.14(95 \% \text { CI } 0.04-0.52)^{7,9)}$; however, these studies only compared the efficacy of anticoagulation with that of no anticoagulation. Moreover, these metaanalyses did not evaluate dual antiplatelet agents (acetylsalicylic acid and clopidogrel), which are common current therapeutics for patients with acute myocardial infarction. Prior studies reported various rates of post-treatment thromboembolism (from $0 \%$ to $33.3 \%$ ) even with adequate anticoagulation. The rate of post-treatment embolism of these studies is as follows: Nihoyannopoulos et al. ${ }^{17)}$ (none of 21 patients), Weinreich et al. ${ }^{18)}$ (none of 25 patients), Stratton et al. ${ }^{6)}$ (2 of 23 patients, 8.7\%), Visser et al. ${ }^{19)}$ (7 of 46 patients, $15.2 \%$ ), Keren et al. ${ }^{20)}$ (6 of 38 patients, 15.8\%), Jugdutt et al. ${ }^{21)}$ (27 of 115 patients, 23.5\%), Haugland et al. ${ }^{5)}$ (5 of 16 patients, 31.3\%) and Johanessen et al. ${ }^{1)}$ (5 of 15 patients, 33.3\%). The overall rate of post-treatment thromboembolism in our anticoagulation group was $17.1 \%$, consistent with previous studies. The reported resolution rate of thrombus with anticoagulation is also variable, ranging from $48 \%$ at 6 months follow-up to $65-85 \%$ at 24 -month followup $^{9,17,20,21)}$. Similarly, the resolution rate of the thrombus in our study was $65.6 \%$ in the anticoagulation group. The remaining chronic thrombus also confers a substantial risk of systemic thromboembolism ${ }^{5,19)}$. These prior studies support our findings that conventional anticoagulation is not able to eliminate the risk of systemic thromboembolism, even with adequate maintenance of anticoagulation, unless the LV thrombus has completely disappeared.

\section{Outcomes of Operative Treatment}

Even though we failed to detect a statistically significant difference in event-free survival between the anticoagulation and operative treatment groups, this tendency towards longer survival in the operative treatment group increased after imbalances in baseline covariates were corrected with propensity score matching. It is noteworthy that the clinical severity of the operative treatment group was greater than that of the other groups. Three of eight patients in the operative treatment group had undergone surgery with mechan- 
Supplementary Table 4. Propensity Score Matching between the Anticoagulation and Antiplatelet Agent Groups*

\begin{tabular}{|c|c|c|c|}
\hline & Anticoagulation $(n=8)$ & Antiplatelet agent $(n=8)$ & $p$ value \\
\hline \multicolumn{4}{|l|}{ Medications } \\
\hline Acetylsalicylic acid & $7(87.5 \%)$ & $8(100 \%)$ & $>0.999$ \\
\hline Clopidogrel & $3(37.5 \%)$ & $6(75.0 \%)$ & 0.315 \\
\hline Dual antiplatelet agents (Aspirin and Clopidogrel) & $3(37.5 \%)$ & $6(75.0 \%)$ & 0.315 \\
\hline \multicolumn{4}{|l|}{ Thrombus Morphology } \\
\hline High-risk thrombus ${ }^{\dagger}$ & $2(25.0 \%)$ & $1(12.5 \%)$ & $>0.999$ \\
\hline Maximum size & $16.63 \pm 5.55$ & $15.06 \pm 9.17$ & 0.342 \\
\hline \multicolumn{4}{|l|}{ Thrombus Outcomes } \\
\hline Follow-up echo & $6(75.0 \%)$ & $6(75.0 \%)$ & $>0.999$ \\
\hline Resolution & $3(50.0 \%)$ & $1(16.7 \%)$ & 0.545 \\
\hline Follow-up size & $10.27 \pm 12.21$ & $13.77 \pm 12.25$ & 0.806 \\
\hline \multicolumn{4}{|l|}{ Clinical Outcomes } \\
\hline Post-treatment & $1(12.5 \%)$ & $1(12.5 \%)$ & $>0.999$ \\
\hline CVA & $0(0 \%)$ & $1(12.5 \%)$ & $>0.999$ \\
\hline Peripheral embolism & $1(12.5 \%)$ & $0(0 \%)$ & $>0.999$ \\
\hline Bleeding event ${ }^{*}$ & $1(12.5 \%)$ & $0(0 \%)$ & $>0.999$ \\
\hline Minor & $1(12.5 \%)$ & $0(0 \%)$ & $>0.999$ \\
\hline
\end{tabular}

* Data are expressed as the means \pm SD or as counts (\%).

${ }^{\dagger}$ High-risk thrombus was defined as mobile or multiple left ventricular thrombi.

\$ Bleeding events were defined according to the Thrombolysis in Myocardial Infarction (TIMI) criteria. Major bleeding was defined as any intracranial hemorrhage, more than a $5 \mathrm{~g} / \mathrm{dL}$ decrease in the hemoglobin concentration or more than a $15 \%$ absolute decrease in the hematocrit.

Abbreviations: CVA, cerebrovascular accident; echo, echocardiography.

ical circulatory support (intra-aortic balloon pump or extracorporeal membrane oxygenation) and 2 of 8 patients $(25 \%)$ had highly mobile or multiple thrombi which embolized preoperatively. Theoretically, complete resolution or treatment of thrombus will eliminate the possibility of systemic thromboembolism. Reports of operative treatment of LV thrombus have been scarce; most such reports are confined to case reports or case series. Previously Nili, M et al. reported 4 cases of surgical removal of LV thrombus; these patients did not develop post-treatment thromboembolism after thrombectomy with or without CABG, similar to our findings ${ }^{22}$. All other reports were case reports of successful removal of an LV thrombus through thrombectomy or video-assisted transaortic removal with excellent postoperative results ${ }^{23-25)}$.

\section{Bleeding Risk of Conventional Anticoagulation}

Conventional anticoagulation is known to confer about a $20 \%$ risk of bleeding ${ }^{6}$; the bleeding rate of our study was $11.9 \%$, including 2 major bleeds, with 1 death due to bleeding. The most serious bleeding complication, intracranial hemorrhage, causes approximately $90 \%$ of deaths and most of the permanent disability in patients with warfarin-associated bleeding ${ }^{26)}$. Anticoagulation with warfarin increases the risk of intracranial hemorrhage by $2-5$-fold $\left.{ }^{27}, 28\right)$. Furthermore, the known propensity of major bleeding to increase mortality is supported by several clinical trials, including the REPLACE-2 trial $^{29)}$ and the TRITON-TIMI 38 trial $^{30}$. The overall hazard ratio of bleeding, including major and minor bleeding, was 5.84 (95\% CI 4.11-8.29) in the TRITON-TIMI 38 trial $^{30)}$. In our study, the risks of major bleeding and mortality associated with bleeding were considerable. Meticulous risk stratification regarding bleeding and systemic thromboembolism should be considered before starting anticoagulation.

\section{Predictors of Embolism}

To facilitate treatment that is more individualized than routine anticoagulation, it is important to establish selection criteria for patients at high-risk of systemic thromboembolism. Through Cox proportional hazard regression modeling, we found that mobile or multiple thrombi were independent predictors of pre-treatment thromboembolism, as previously reported $^{1,5,6,19,21)}$. Initial presentation with cardiac arrest was also a significant independent predictor of pre-treatment embolism. Severe LV dysfunction due to chronic myocardial infarction or symptomatic heart failure is a well-known risk factor for cerebral infarc- 
Supplementary Table 5. Baseline Characteristics and Clinical Outcomes According to the Underlying Heart Condition (Ischemic Etiology versus Non-ischemic Etiology)*

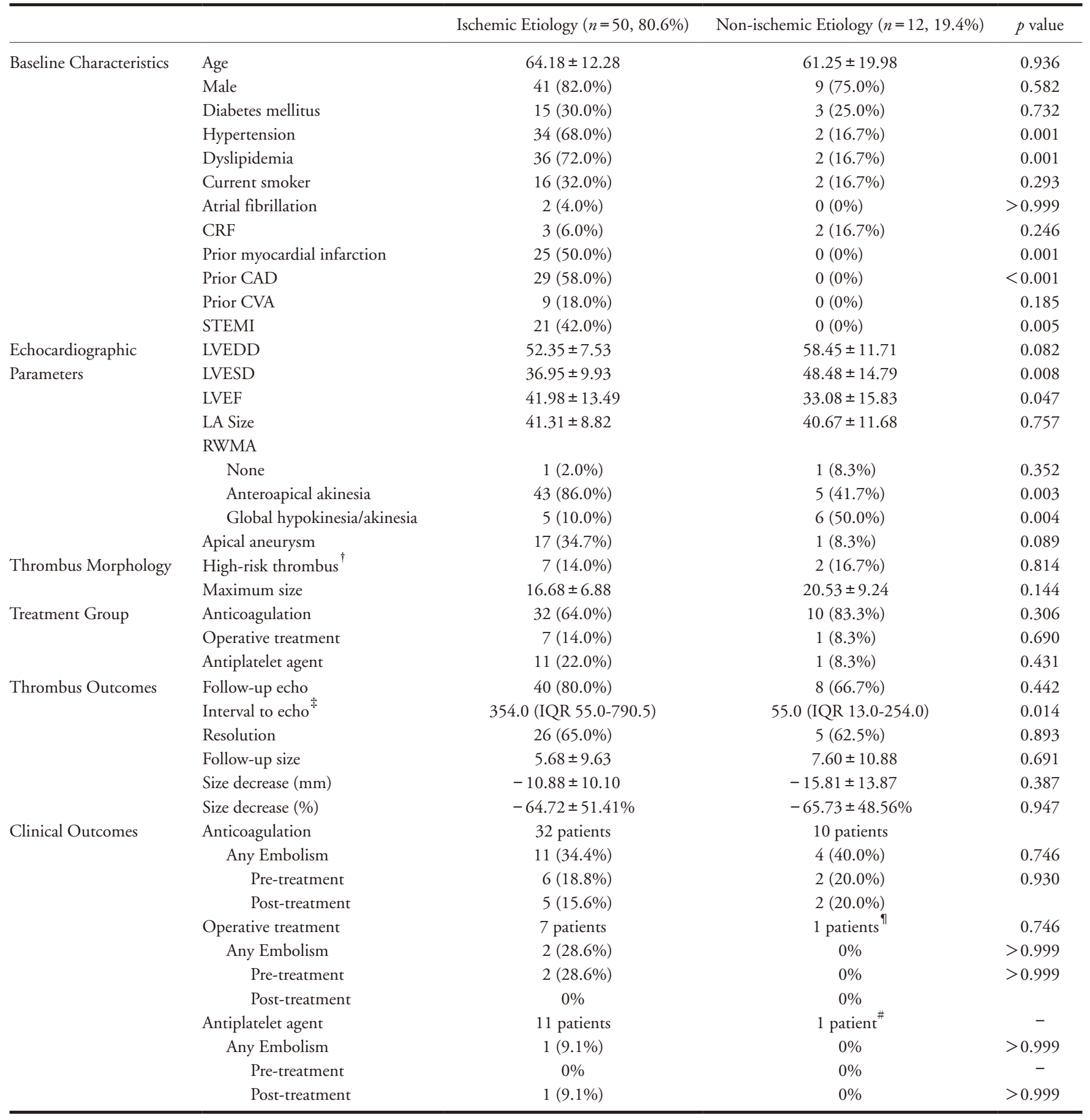

\footnotetext{
* Data are expressed as the means \pm SD or as counts (\%). Non-ischemic cardiomyopathy included 5 patients with dilated cardiomyopathy, 3 with stress-induced cardiomyopathy, 2 with hypertrophic cardiomyopathy, and 2 patients with severe aortic stenosis and Brugada syndrome, respectively. ${ }^{\dagger}$ High-risk thrombus was defined as either a mobile thrombus, including pedunculated thrombus, or multiple left ventricular thrombi.

" Interval to follow-up echocardiography, data are expressed as the median and interquartile range.

"One patient with severe aortic stenosis with LV thrombus was treated with operative treatment (aortic valve replacement with LV thrombectomy).

\# One patient with stress-induced cardiomyopathy was treated only with antiplatelet agent.

Abbreviations: CAD, coronary artery disease; CRF, chronic renal failure; IQR, interquartile range; LA, left atrium; LAVI, left atrium volume index; LVEDD, left ventricular end-diastolic dimension; LVESD, left ventricular end-systolic dimension; RWMA, regional wall motion abnormality; STEMI, ST segment elevation myocardial infarction.
} 
Table 5. Independent Risk Factors for Systemic Thromboembolism

\begin{tabular}{lccc}
\hline \multicolumn{1}{c}{ Variables } & Adjusted HR & $95 \%$ CI & $p$ value \\
\hline $\begin{array}{l}\text { Pre-treatment embolism } \\
\quad \text { Cardiac arrest }\end{array}$ & 82.28 & $4.51-1502.53$ & 0.003 \\
$\quad$ Mobile/Multiple thrombi & 13.75 & $1.36-138.27$ & 0.026 \\
Post-treatment embolism & & & \\
$\quad$ Female & 7.11 & $1.19-42.35$ & 0.031 \\
Prior CVA & 7.06 & $1.08-46.24$ & 0.042 \\
DCMP & 61.30 & $5.10-736.11$ & 0.001 \\
LVEDD (per 1 mm) & 1.15 & $1.00-1.31$ & 0.047 \\
\hline
\end{tabular}

Abbreviations: CVA, cerebrovascular accident; CI, confidence interval; DCMP, dilated cardiomyopathy; HR, hazard ratio; LVEDD, left ventricular end-diastolic dimension.

tion $^{31)}$. Myocardial dysfunction, including severe LV dysfunction or symptomatic heart failure, is a common manifestation in survivors of cardiac arrest ${ }^{32)}$; therefore, cardiac arrest might be the precipitating cause of embolic cerebral infarction.

Since pre-treatment embolism is difficult to prevent, it is more important to indentify predictors of post-treatment embolism. In this study, a prior cerebrovascular accident, idiopathic DCMP and large LVEDD were found to be independent predictors of post-treatment embolism. Recently, Sharma et al. reported that LVEDD was significantly associated with the development of LV thrombus but not with systemic thromboembolism, and predictors of systemic thromboembolism were ischemic cardiomyopathy and low $\mathrm{EF}^{4)}$. In contrast, in the current study, idiopathic DCMP (but not ischemic cardiomyopathy) was the most powerful predictor of systemic thromboembolism. However, DCMP and a previous history of cerebral infarction or transient ischemic attack are already known to be strong risk factors for cardiogenic embolism and cerebral infarction ${ }^{33)}$. All patients with DCMP were treated with anticoagulation; this uneven distribution of treatment modality could be one of the reasons that DCMP was found to be an independent predictor; however, DCMP remained an independent predictor of post-treatment thromboembolism after adjusting for the treatment modality and underlying heart condition.

Interestingly, female gender was also an independent predictor of post-treatment thromboembolism. In the literature, there is no clear explanation of why female gender was associated with increased thromboembolic risk. Recently, female gender was reported to be associated with an increased risk for clopidogrel hypo-responsiveness ${ }^{34,35)}$. Gender-specific differences exist in the activity of CYP enzymes ${ }^{36}$. Men have increased CYP1A2 activity, while women have increased CYP3A4 activity. Warfarin undergoes extensive metabolism by the cytochrome $\mathrm{P} 450$ isoforms. CYP2C9 is responsible for the metabolism of S-warfarin, while R-warfarin is metabolized by CYP1A2, CYP2C19 and CYP3A4 ${ }^{37)}$. Enhanced activity of CYP3A4 in women would increase warfarin clearance compared to in men. Furthermore, differences in the hormonal status (menopause) could influence thrombogenicity. Taken together, differences in CYP enzyme activity and the hormonal status might affect the response to clopidogrel and warfarin use in women. Of note, sex differences in ischemic stroke or postoperative stroke after carotid endarterectomy were frequently described ${ }^{38,39)}$.

These aforementioned high-risk patients for posttreatment embolism need to be more aggressively treated and closely followed.

\section{Limitations}

Some important limitations of this study should be considered. First, this study was performed using a single center database with a relatively small number of patients, which might have lacked statistical power to detect differences in the primary outcome among treatment groups. Second, this study was a retrospective, descriptive study that could not control for unmeasured confounders. Even though we used propensity score matching and Cox proportional hazard regression modeling to minimize the influence of potential confounders, the possible influences of uncontrolled and unknown confounding factors should be considered. In addition, there were no data regarding the presence of thrombophilia, for example, protein $\mathrm{C}, \mathrm{S}$ or antithrombin deficiency or antiphospholipid antibody syndrome, because thrombophilia evaluation is not routinely performed in our hospital. However, obesity and impaired renal function, which 
Supplementary Table 6. Baseline clinical and thrombus characteristic in patients with non-ischemic etiology*

\begin{tabular}{|c|c|c|c|c|}
\hline Characteristics & $\begin{array}{c}\text { Total } \\
(n=12)\end{array}$ & $\begin{array}{c}\text { Embolism }(-) \\
(n=10,83.3 \%)\end{array}$ & $\begin{array}{l}\text { Embolism }(+) \\
(n=2,16.7 \%)\end{array}$ & $p$ value \\
\hline \multicolumn{5}{|l|}{ Baseline Characteristics } \\
\hline Age & $61.25 \pm 19.98$ & $64.20 \pm 20.43$ & $46.50 \pm 10.61$ & 0.237 \\
\hline Male & $9(75.0 \%)$ & $8(80.0 \%)$ & $1(50.0 \%)$ & 0.455 \\
\hline Diabetes mellitus & $3(25.0 \%)$ & $8(80.0 \%)$ & $1(50.0 \%)$ & 0.455 \\
\hline Hypertension & $2(16.7 \%)$ & $2(20.0 \%)$ & $0 \%$ & $>0.999$ \\
\hline Dyslipidemia & $2(16.7 \%)$ & $2(20.0 \%)$ & $0 \%$ & $>0.999$ \\
\hline Current smoker & $2(16.7 \%)$ & $1(10.0 \%)$ & $1(50.0 \%)$ & 0.318 \\
\hline Atrial fibrillation ${ }^{\dagger}$ & $0 \%$ & $0 \%$ & $0 \%$ & - \\
\hline CRF & $2(16.7 \%)$ & $2(20.0 \%)$ & $0 \%$ & $>0.999$ \\
\hline $\mathrm{eGFR}^{\ddagger}$ & $69.87 \pm 40.95$ & $75.07 \pm 42.83$ & $43.85 \pm 17.75$ & 0.197 \\
\hline Malignancy & $1(8.3 \%)$ & $1(10.0 \%)$ & $0(0 \%)$ & $>0.999$ \\
\hline Prior myocardial infarction & $0 \%$ & $0 \%$ & $0 \%$ & - \\
\hline Prior CAD & $0 \%$ & $0 \%$ & $0 \%$ & - \\
\hline Prior CVA & $0 \%$ & $0 \%$ & $0 \%$ & - \\
\hline \multicolumn{5}{|l|}{ Underlying Heart Conditions } \\
\hline Ichemic CMP & $0 \%$ & $0 \%$ & $0 \%$ & - \\
\hline Dilated CMP & $5(41.7 \%)$ & $3(30.0 \%)$ & $2(100.0 \%)$ & 0.152 \\
\hline Apical HCMP & $2(16.7 \%)$ & $2(20.0 \%)$ & $0(0 \%)$ & $>0.999$ \\
\hline Stress-induced CMP & $3(25.0 \%)$ & $3(30.0 \%)$ & $0(0 \%)$ & 0.550 \\
\hline Severe AS & $1(1.6 \%)$ & $1(10.0 \%)$ & $0 \%$ & $>0.999$ \\
\hline Cardiac arrest due to Brugada syndrome & $1(1.6 \%)$ & $1(10.0 \%)$ & $0 \%$ & $>0.999$ \\
\hline \multicolumn{5}{|l|}{ Thrombus Morphology } \\
\hline Maximum size & $20.53 \pm 9.24$ & $8.79 \pm 2.78$ & $15.56 \pm 11.00$ & $>0.999$ \\
\hline Apical location & $62(100 \%)$ & $44(100 \%)$ & $18(100 \%)$ & NS \\
\hline Mobile/Multiple & $9(14.5 \%)$ & $4(9.1 \%)$ & $5(27.8 \%)$ & 0.058 \\
\hline Mural/Sessile & $53(85.5 \%)$ & $40(90.9 \%)$ & $13(72.2 \%)$ & 0.058 \\
\hline \multicolumn{5}{|l|}{ Echocardiographic Parameters } \\
\hline LVEDD & $58.45 \pm 11.71$ & $52.72 \pm 8.58$ & $74.15 \pm 12.52$ & 0.053 \\
\hline LVESD & $48.48 \pm 14.79$ & $44.80 \pm 12.59$ & $66.90 \pm 12.87$ & 0.133 \\
\hline LVEF & $33.08 \pm 15.83$ & $35.60 \pm 16.11$ & $20.50 \pm 8.36$ & 0.196 \\
\hline \multicolumn{5}{|l|}{ RWMA } \\
\hline None & $1(8.3 \%)$ & $1(10.0 \%)$ & $0(0 \%)$ & $>0.999$ \\
\hline Anteroapical akinesia & $5(41.7 \%)$ & $5(50.0 \%)$ & $0(0 \%)$ & 0.470 \\
\hline Global hypokinesia/akinesia & $6(50.0 \%)$ & $4(40.0 \%)$ & $2(100.0 \%)$ & 0.455 \\
\hline Apical aneurysm & $1(8.3 \%)$ & $1(10.0 \%)$ & $0(0 \%)$ & $>0.999$ \\
\hline
\end{tabular}

* Data are expressed as the means \pm SD or as counts (\%).

Atrial fibrillation included both permanent and paroxysmal atrial fibrillation.

${ }^{\$}$ Estimated glomerular filtration rate $\left(\mathrm{mL} / \mathrm{min} / 1.73 \mathrm{~m}^{2}\right)$ was calculated by MDRD (Modification of Diet in Renal Disease) equation.

Abbreviations: AS, aortic stenosis; CAD, coronary artery disease; CMP, cardiomyopathy; CRF, chronic renal failure; CVA, cerebrovascular accident; eGFR, estimated glomerular filtration rate; HCMP, hypertrophic cardiomyopathy; LVEDD, left ventricular end-diastolic dimension; LVESD, left ventricular end-systolic dimension; LVEF, left ventricular ejection fraction; RWMA, regional wall motion abnormality.

are also associated with enhanced thrombogenesis ${ }^{40,41)}$, were evaluated as independent predictors of posttreatment thromboembolism; we did not find a notable association with post-treatment thromboembolism. Third, the limited sensitivity of TTE for the detection of LV thrombus may have underestimated the recur- rence of LV thrombus. Fourth, the uneven distribution of the patients among the treatment groups and possible allocation bias should be considered. All patients with dilated cardiomyopathy were treated with anticoagulation; hence, this study could not compare treatment modalities for this subgroup. All 
patients in the operative treatment group had another absolute indication for open heart surgery, i.e. 3-vessel disease requiring CABG or severe aortic stenosis requiring aortic valve replacement. While the operative treatment group had the potential for improvement of their left ventricular function, most of the patients in the conventional anticoagulation group had low potential for improvement of their left ventricular function.

All statements about the possible superiority of operative treatment should be taken as hypothesis generating. In fact, it is difficult to recommend openheart surgery to patients whose only indication is LV thrombus; however, our study reflects the current management of LV thrombus. Nonetheless, in patients with a high-risk profile, surgical removal might reduce the incidence of thromboembolism more than anticoagulation therapy. It is unknown whether the reduction in post-treatment thromboembolism outweighs the risk of surgery related morbidity and mortality. Nevertheless, to the best of our knowledge, the current study is the first report to compare the long-term efficacy and consequences of anticoagulation, operative treatment, and antiplatelet agents for the treatment of LV thrombus. We expect that these limitations will be more appropriately addressed in future randomized trials comparing anticoagulation with operative treatment in patients with LV thrombus.

\section{Conclusion}

The rate of post-treatment thromboembolism did not differ significantly among the three treatment groups. Nonetheless, we observed a tendency towards a lower rate of post-treatment embolism in the operative treatment group. Given the risk of bleeding and insufficient resolution rate with anticoagulation, alternative or additive treatment, especially for patients at high risk for systemic thromboembolism should be considered. Further prospective randomized controlled studies are needed to clarify these issues.

\section{Acknowledgments}

Financial/nonfinancial disclosures: The authors have no potential conflicts of interest with any companies/organizations whose products or services were discussed in this article.

\section{Conflict of Interest}

None.

\section{References}

1) Johannessen KA, Nordrehaug JE, von der Lippe G: Left ventricular thrombosis and cerebrovascular accident in acute myocardial infarction. Br Heart J, 1984; 51: 553556

2) Asinger RW, Mikell FL, Elsperger J, Hodges M: Incidence of left-ventricular thrombosis after acute transmural myocardial infarction. Serial evaluation by two-dimensional echocardiography. N Engl J Med, 1981; 305: 297-302

3) de Gregorio C: Cardioembolic outcomes in stress-related cardiomyopathy complicated by ventricular thrombus: a systematic review of 26 clinical studies. Int J Cardiol, 2010; 141: 11-17

4) Sharma ND, McCullough PA, Philbin EF, Weaver WD: Left ventricular thrombus and subsequent thromboembolism in patients with severe systolic dysfunction. Chest, 2000; 117: 314-320

5) Haugland JM, Asinger RW, Mikell FL, Elsperger J, Hodges M: Embolic potential of left ventricular thrombi detected by two-dimensional echocardiography. Circulation, 1984; 70: 588-598

6) Stratton JR, Resnick AD: Increased embolic risk in patients with left ventricular thrombi. Circulation, 1987; 75: 10041011

7) Vaitkus PT, Barnathan ES: Embolic potential, prevention and management of mural thrombus complicating anterior myocardial infarction: a meta-analysis. J Am Coll Cardiol, 1993; 22: 1004-1009

8) Kontny F, Dale J, Abildgaard U, Pedersen TR: Randomized trial of low molecular weight heparin (dalteparin) in prevention of left ventricular thrombus formation and arterial embolism after acute anterior myocardial infarction: the Fragmin in Acute Myocardial Infarction (FRAMI) Study. J Am Coll Cardiol, 1997; 30: 962-969

9) van Dantzig JM, Delemarre BJ, Bot H, Visser CA: Left ventricular thrombus in acute myocardial infarction. Eur Heart J, 1996; 17: 1640-1645

10) Antman EM, Anbe DT, Armstrong PW, Bates ER, Green LA, Hand M, Hochman JS, Krumholz HM, Kushner FG, Lamas GA, Mullany CJ, Ornato JP, Pearle DL, Sloan MA, Smith SC Jr, Alpert JS, Anderson JL, Faxon DP, Fuster V, Gibbons RJ, Gregoratos G, Halperin JL, Hiratzka LF, Hunt SA, Jacobs AK: ACC/AHA guidelines for the management of patients with ST-elevation myocardial infarction--executive summary: a report of the American College of Cardiology/American Heart Association Task Force on Practice Guidelines (Writing Committee to Revise the 1999 Guidelines for the Management of Patients With Acute Myocardial Infarction). Circulation, 2004; 110: 588-636

11) Schiller NB, Shah PM, Crawford M, DeMaria A, Devereux R, Feigenbaum H, Gutgesell H, Reichek N, Sahn D, Schnittger I, et al: Recommendations for quantitation of the left ventricle by two-dimensional echocardiography. American Society of Echocardiography Committee on Standards, Subcommittee on Quantitation of Two-Dimensional Echocardiograms. J Am Soc Echocardiogr, 1989; 2: 358-367

12) Hart RG, Coull BM, Hart D: Early recurrent embolism 
associated with nonvalvular atrial fibrillation: a retrospective study. Stroke, 1983; 14: 688-693

13) Cutlip DE, Windecker S, Mehran R, Boam A, Cohen DJ, van Es GA, Gabriel Steg P, Morel Ma, Mauri L, Vranckx P, McFadden E, Lansky A, Hamon M, Krucoff MW, Serruys PW: Clinical End Points in Coronary Stent Trials: A Case for Standardized Definitions. Circulation, 2007; 115: 2344-2351

14) Chesebro JH, Knatterud G, Roberts R, Borer J, Cohen LS, Dalen J, Dodge HT, Francis CK, Hillis D, Ludbrook $\mathrm{P}$, et al: Thrombolysis in Myocardial Infarction (TIMI) Trial, Phase I: A comparison between intravenous tissue plasminogen activator and intravenous streptokinase. Clinical findings through hospital discharge. Circulation, 1987; 76: 142-154

15) Gu XS, Rosenbaum PR: Comparison of Multivariate Matching Methods: Structures, Distances, and Algorithms. Journal of Computational and Graphical Statistics, 1993; 2: 405-420

16) Kovacevic-Preradovic T, Jenni R, Oechslin EN, Noll G, Seifert B, Attenhofer Jost CH: Isolated left ventricular noncompaction as a cause for heart failure and heart transplantation: a single center experience. Cardiology, 2009; 112: 158-164

17) Nihoyannopoulos P, Smith GC, Maseri A, Foale RA: The natural history of left ventricular thrombus in myocardial infarction: a rationale in support of masterly inactivity. J Am Coll Cardiol, 1989; 14: 903-911

18) Weinreich DJ, Burke JF, Pauletto FJ: Left ventricular mural thrombi complicating acute myocardial infarction. Long-term follow-up with serial echocardiography. Ann Intern Med, 1984; 100: 789-794

19) Visser CA, Kan G, Meltzer RS, Dunning AJ, Roelandt J: Embolic potential of left ventricular thrombus after myocardial infarction: a two-dimensional echocardiographic study of 119 patients. J Am Coll Cardiol, 1985; 5: 12761280

20) Keren A, Goldberg S, Gottlieb S, Klein J, Schuger C, Medina A, Tzivoni D, Stern S: Natural history of left ventricular thrombi: their appearance and resolution in the posthospitalization period of acute myocardial infarction. J Am Coll Cardiol, 1990; 15: 790-800

21) Jugdutt BI, Sivaram CA: Prospective two-dimensional echocardiographic evaluation of left ventricular thrombus and embolism after acute myocardial infarction. J Am Coll Cardiol, 1989; 13: 554-564

22) Nili M, Deviri E, Jortner R, Strasberg B, Levy MJ: Surgical removal of a mobile, pedunculated left ventricular thrombus: report of 4 cases. Ann Thorac Surg, 1988; 46: 396-400

23) Duarte IG, Fenton KN, Brown WM, 3rd: Video-assisted removal of left ventricular mass. Ann Thorac Surg, 1997; 63: 833-835

24) Kanemitsu S, Miyake Y, Okabe M: Surgical removal of a left ventricular thrombus associated with cardiac sarcoidosis. Interact Cardiovasc Thorac Surg, 2008; 7: 333-335

25) Minami H, Asada T, Gan K: Surgical removal of left ventricular ball-like thrombus following large transmural acute myocardial infarction using the infarction exclusion technique: David-Komeda procedure. Circ J, 2008; 72:
1547-1549

26) Fang MC, Go AS, Chang Y, Hylek EM, Henault LE, Jensvold NG, Singer DE: Death and disability from warfarin-associated intracranial and extracranial hemorrhages. Am J Med, 2007; 120: 700-705

27) Hart RG, Tonarelli SB, Pearce LA: Avoiding central nervous system bleeding during antithrombotic therapy: recent data and ideas. Stroke, 2005; 36: 1588-1593

28) Rosand J, Eckman MH, Knudsen KA, Singer DE, Greenberg SM: The effect of warfarin and intensity of anticoagulation on outcome of intracerebral hemorrhage. Arch Intern Med, 2004; 164: 880-884

29) Feit F, Voeltz MD, Attubato MJ, Lincoff AM, Chew DP, Bittl JA, Topol EJ, Manoukian SV: Predictors and impact of major hemorrhage on mortality following percutaneous coronary intervention from the REPLACE-2 Trial. Am J Cardiol, 2007; 100: 1364-1369

30) Hochholzer W, Wiviott SD, Antman EM, Contant CF, Guo J, Giugliano RP, Dalby AJ, Montalescot G, Braunwald E: Predictors of bleeding and time dependence of association of bleeding with mortality: insights from the Trial to Assess Improvement in Therapeutic Outcomes by Optimizing Platelet Inhibition With Prasugrel--Thrombolysis in Myocardial Infarction 38 (TRITON-TIMI 38). Circulation, 2011; 123: 2681-2689

31) Ay H, Furie KL, Singhal A, Smith WS, Sorensen AG, Koroshetz WJ: An evidence-based causative classification system for acute ischemic stroke. Ann Neurol, 2005; 58: 688-697

32) Ruiz-Bailen M, Aguayo de Hoyos E, Ruiz-Navarro S, DiazCastellanos MA, Rucabado-Aguilar L, Gomez-Jimenez FJ, Martinez-Escobar S, Moreno RM, Fierro-Roson J: Reversible myocardial dysfunction after cardiopulmonary resuscitation. Resuscitation, 2005; 66: 175-181

33) Doufekias E, Segal AZ, Kizer JR: Cardiogenic and aortogenic brain embolism. J Am Coll Cardiol, 2008; 51: 1049-1059

34) Park KW, Park JJ, Jeon KH, Kang SH, Oh IY, Yang HM, Cho HJ, Lee HY, Kang HJ, Koo BK, Oh BH, Park YB, Kim HS: Clinical predictors of high posttreatment platelet reactivity to clopidogrel in Koreans. Cardiovasc Ther, 2012; 30: 5-11

35) Price MJ, Nayak KR, Barker CM, Kandzari DE, Teirstein PS: Predictors of heightened platelet reactivity despite dualantiplatelet therapy in patients undergoing percutaneous coronary intervention. Am J Cardiol, 2009; 103: 13391343

36) Scandlyn MJ, Stuart EC, Rosengren RJ: Sex-specific differences in CYP450 isoforms in humans. Expert Opin Drug Metab Toxicol, 2008; 4: 413-424

37) Wienkers LC, Wurden CJ, Storch E, Kunze KL, Rettie AE, Trager WF: Formation of (R)-8-hydroxywarfarin in human liver microsomes. A new metabolic marker for the (S)-mephenytoin hydroxylase, P4502C19. Drug Metab Dispos, 1996; 24: 610-614

38) Turtzo LC, McCullough LD: Sex differences in stroke. Cerebrovasc Dis, 2008; 26: 462-474

39) Vouyouka AG, Kent KC: Arterial vascular disease in women. J Vasc Surg, 2007; 46: 1295-1302

40) Mezzano D, Espana F, Panes O, Medina P, Pais E, Mar- 
shall G, Tagle R, Downey P, Caceres S, Gonzalez F, Quiroga T, Pereira J: Increased activation of protein C, but lower plasma levels of free, activated protein $\mathrm{C}$ in uraemic patients: relationship with systemic inflammation and haemostatic activation. Br J Haematol, 2001; 113:
905-910

41) Goldhaber SZ, Grodstein F, Stampfer MJ, Manson JE, Colditz GA, Speizer FE, Willett WC, Hennekens CH: A prospective study of risk factors for pulmonary embolism in women. JAMA, 1997; 277: 642-645 


\section{Supplementary Materials}

\section{Detailed Imaging Protocols of Cardiac MRI and Coronary CT angiography Cardiac MRI}

The imaging protocol included the following techniques/pulse sequences: 1) LV mass and function: Balanced steady-state free precession (SSFP) gradient echo cine loops were acquired in both two-chamber and four-chamber views. Parameters were TR 3.54 $\mathrm{ms}$, TE $1.77 \mathrm{~ms}$, flip angle 60, FoV $350 \mathrm{~mm} \times 350$ $\mathrm{mm}$, matrix $192 \times 190$, in-plane resolution: $1.82 \mathrm{~mm}$ $\times 1.84 \mathrm{~mm}, 30$ phases per cardiac cycle, and number of signal average 1.00 . Slice thickness was $8 \mathrm{~mm}$ without an interslice gap. 2) T2-weighted imaging: Tripleinverted fast spin echo images were acquired in short axis orientation (TR, $1714.29 \mathrm{~ms}$; TE, $100.00 \mathrm{~ms}$; TI, $550 \mathrm{~ms}$ and slice thickness $8 \mathrm{~mm}$ without an interslice gap) using the cardiac coil. 3) Early gadolinium enhancement: Axial T1-weighted fast spin echo images (TR, $2.68 \mathrm{~ms}$; TE, $1.34 \mathrm{~ms}$; flip angle $50^{\circ}$; FoV $335 \times 360$; matrix $128 \times 121$ and in-plane resolution $2.61 \mathrm{~mm} \times 2.97 \mathrm{~mm}$ ) were obtained before and during the first $4 \mathrm{~min}$ immediately after administration of $0.1 \mathrm{mmol} / \mathrm{kg}$ Gadolinium-DTPA (OMNISCAN; GE Healthcare, Waukesha, WI, USA). The cardiac coil was used for signal acquisition. 4) Late gadolinium enhancement (LGE): After testing different inversion times (180-350 ms) for optimal suppression of the myocardium, contiguous stacks of long- and short-axis DE inversion recovery-prepared fast low angle shot gradient echo images were obtained 10-15 min after administration of a second bolus of contrast agent $(0.1 \mathrm{mmol} / \mathrm{kg})$. Parameters were TR $4.63 \mathrm{~ms}$, TE $1.50 \mathrm{~ms}$, flip angle 15, and number of signal average 3.00. Slice thickness was $8 \mathrm{~mm}$ on long axis and short axis images.

\section{Coronary CT Angiography}

All subjects underwent coronary CTA with retrospective ECG gating on a 64-channel Multi-Detector Computed Tomography (MDCT) scanner (Brilliance iCT; Philips Medical System, Boston, MA, USA). Anteroposterior and lateral topograms were followed by prospectively ECG-triggered unenhanced calcium scoring acquisition. A bolus tracking method was routinely used. Then, 50-70 mL of a mixture of iomeprol (Iomeron 400; Bracco, Milan, Italy) nonionic IV contrast medium and saline (4:6 ratio) was administered through a triphasic bolus power injector (Stellant; Medrad, (city, state?) USA) at a rate of $4 \mathrm{~mL} / \mathrm{s}$. The scan delay for each patient was determined with an automatic bolus tracking system with a threshold of $200 \mathrm{HU}$ at the descending thoracic aorta. Coronary CTA acquisition was performed with a scan delay of peak plus 8.2 seconds with the following parameters: gantry rotation time, 0.27 seconds; slice thickness, 0.9 $\mathrm{mm}$; interval, $0.45 \mathrm{~mm} ; \mathrm{kVp} / \mathrm{mAs} 120 / 800$; image matrix $512 \times 512$ and pitch, 0.18 . We used ECG modulation for all patients $(100 \%$ peak tube current in mid-diastole, up to $80 \%$ reduction during systole) to reduce radiation exposure. The images were postprocessed at a workstation (Extended Brilliance Workspace, Version 4.0; Philips Medical System). 